OPEN ACCESS

Edited by:

Julia M. Lappin,

University of New South Wales,

Australia

Reviewed by:

Domenico De Berardis,

Azienda Usl Teramo, Italy

Fleur Margaret Howells,

University of Cape Town, South Africa

*Correspondence:

Jennifer L. Cornish

jennifer.cornish@mq.edu.au

Specialty section:

This article was submitted to

Addictive Disorders,

a section of the journal

Frontiers in Psychiatry

Received: 28 June 2018 Accepted: 19 September 2018

Published: 10 October 2018

Citation:

Wearne TA and Cornish JL (2018) A Comparison of

Methamphetamine-Induced

Psychosis and Schizophrenia: A Review of Positive, Negative, and

Cognitive Symptomatology.

Front. Psychiatry 9:491

doi: 10.3389/fpsyt.2018.00491

\section{A Comparison of Methamphetamine-Induced Psychosis and Schizophrenia: A Review of Positive, Negative, and Cognitive Symptomatology}

\author{
Travis A. Wearne ${ }^{1,2}$ and Jennifer L. Cornish ${ }^{1 *}$ \\ ${ }^{1}$ Department of Psychology, Macquarie University, Sydney, NSW, Australia, ${ }^{2}$ School of Psychology, University of New South \\ Wales, Sydney, NSW, Australia
}

Methamphetamine is a potent psychostimulant that can induce psychosis among recreational and chronic users, with some users developing a persistent psychotic syndrome that shows similarities to schizophrenia. This review provides a comprehensive critique of research that has directly compared schizophrenia with acute and chronic METH psychosis, with particular focus on psychiatric and neurocognitive symptomatology. We conclude that while there is considerable overlap in the behavioral and cognitive symptoms between METH psychosis and schizophrenia, there appears to be some evidence that suggests there are divergent aspects to each condition, particularly with acute METH psychosis. Schizophrenia appears to be associated with pronounced thought disorder, negative symptoms more generally and cognitive deficits mediated by the parietal cortex, such as difficulties with selective visual attention, while visual and tactile hallucinations appear to be more prevalent in acute METH-induced psychosis. As such, acute METH psychosis may represent a distinct psychotic disorder to schizophrenia and could be clinically distinguished from a primary psychotic disorder based on the aforementioned behavioral and cognitive sequelae. Preliminary evidence, on the other hand, suggests that chronic METH psychosis may be clinically similar to that of primary psychotic disorders, particularly with respect to positive and cognitive symptomatology, although negative symptoms appear to be more pronounced in schizophrenia. Limitations of the literature and avenues for future research are also discussed.

Keywords: methamphetamine, psychosis, schizophrenia, positive symptoms, negative symptoms, cognition

\section{METHAMPHETAMINE}

Amphetamines refer to a class of chemically related compounds that have been used extensively over the last century in both recreational and medicinal settings, with various amphetamine analogs used in the treatment of narcolepsy, attention deficit hyperactivity disorder (ADHD) and obesity $(1,2)$. Methamphetamine (METH; N-methyl-alpha-methylphenethylamine) is a highly potent amphetamine derivative that is frequently abused worldwide and has significant effects 
on physical, behavioral, cognitive and psychiatric output (3). It is a cationic molecule and chiral compound based around a phenylethylamine core (4), and distinguishable from its amphetamine analogs by an additional methyl group. This methyl addition reportedly makes METH highly lipophilic, thereby allowing it to increasingly penetrate the blood-brain barrier (5). This causes changes to dopaminergic, serotonergic, and noradrenergic systems via the stimulated release of monoamines, the inhibition and reversal of monoamine reuptake, inactivation of presynaptic vesicular monoamine transporter 2, and by reducing the efficacy of monoamine metabolic enzymes (6-10). Although all three monoamine systems are involved, the behavioral and reinforcing properties of METH have typically been associated with dopaminergic neurotransmission, particularly in the mesocorticolimbic pathway $(11,12)$.

Epidemiological studies place amphetamine-type stimulants as the most widely used illicit drug in the world after cannabis $(13,14)$, with up to 51 million users globally between 15 and 64 years old (15-17). Worldwide statistics on METH use describe it as a global phenomenon, with METH consumption reportedly independent of wealth, geographical location, and culture (18). Recent reports suggest an increased production of METH around the world and an increasing popularity of METH over the last 5-15 years, which has been linked to increased ease and costeffective synthesis in clandestine laboratories and augmented importation of METH from Mexico and Asia $(16,19)$. Indeed, worldwide seizures relating to METH have been greater than any other drug category (17). Additionally, admissions to treatment programs for METH use increased 255\% from 1997 to 2007 in the USA $(20,21)$, although there is some evidence that the rate of admissions for METH in the USA have remained stable or slightly declined from 2004 to 2014 (22). In Australia, there has been a $233 \%$ increase in demand for METH related treatment and a $274 \%$ increase in METH related hospital admissions since $2010(23,24)$, with Queensland specifically witnessing a 20-fold increase in METH related hospital admissions from 2009 to 2015 (25).

METH is available in various forms and at different levels of chemical purity. When injected, snorted, or inhaled, METH has direct access to the circulatory system and therefore has more immediate effects on the brain $(26,27)$. Given that the negative consequences of METH are associated with the use of more potent forms of the drug and with hazardous routes of administration (i.e., injection), the increased availability of crystalline METH on the illegal market had resulted in a significant increase in METH's popularity amongst dependent and intravenous drug-taking populations (28). Indeed, while $22 \%$ of METH users reported that crystallized METH was their drug of choice in 2010 (29), this had increased to $50 \%$ by 2013 (30). These trends are salient given the potential for addiction and overdose with more potent forms of METH administration.

\section{ACUTE METHAMPHETAMINE PSYCHOSIS}

Dependency to METH, together with high doses and recreational METH use, have all been associated with the induction of psychotic symptoms, including auditory and visual hallucinations, persecutory delusions, ideas of reference, and disorganized speech (31-33). The idea that METH use could induce a psychotic state has long been recognized by clinicians in Japan, who increasingly observed psychosis in their METH-dependent patients (34). The early identification of this relationship was due, in part, to the high prevalence of METH use together with the absence of polydrug use, thereby enabling clinicians to isolate the link between METH and psychosis without the confound of additional substance use (35).

Research has shown that METH psychosis is a prevalent health concern among recreational users. Studies on prevalence rates have varied between $7 \%$ (32) up to $76 \%$ (36), with a recent meta-analysis indicating that the prevalence of $\mathrm{METH}-$ induced psychotic disorder was $36.5 \%$ (37) and these rates were higher for lifetime prevalence $(42.7 \%)$ and for those with METH use disorder (43.3\%). In an Australian study of nontreatment seeking METH users, $13 \%$ of the sample population were positive for psychosis at the time of assessment (32) while $23 \%$ reported 'clinically significant' symptoms of psychosis over the previous year. Another study found that $60 \%$ of METHdependent individuals sampled in the USA reported at least one type of psychotic symptom (38). Overall, recreational METH users are two to three times more likely to experience psychotic symptoms than the general population (39), with their risk increasing if they began using METH at a younger age or if large amounts of METH are administered (40). Regular METH users, on the other hand, are 11 times more likely to experience psychosis than the general population (41), with the average time between first use and onset of psychosis being 1.7 years (42). Furthermore, users of crystallized METH are more likely to report psychotic symptoms compared to other forms of METH (43), suggesting that the type and route of administration may be important factors in determining the likelihood of psychotic symptoms.

Users are more susceptible to the psychotic effects of METH whilst they are using the drug. McKetin et al. (15) found that chronic METH users were 5 times more likely to experience psychotic symptoms during periods of METH use than during periods of abstinence. They also found a dose-response effect between the frequency of METH use and psychotic symptoms, with psychosis reaching a peak likelihood of $48 \%$ following 16 days or more of chronic use. Importantly, these findings were still significant after controlling for polydrug use, suggesting that the psychotic symptoms were attributable to the effects of METH and not due to the interaction of additional drug consumption. Overall, these findings suggest that METH use is associated with a high prevalence of psychotic symptoms, which may present a significant burden on the healthcare system due to increased demand for care and management of METH-related psychoses. Indeed, METH psychosis accounted for $10 \%$ of admissions to psychiatric facilities in Thailand (44), and in Australia, METH psychosis was responsible for 10.3 hospital admissions per 1,000 (45). More recent data has also suggested an increase in $\mathrm{METH}$ psychosis admissions to hospital emergency rooms and psychiatric facilities over recent years. For example, the number of admissions to psychiatric units for METH psychosis in Queensland has increased significantly from 2012 (25) while in New South Wales, Australia, the number of hospital admissions 
for METH psychosis declined in the mid-2000s but have steadily increased again since 2010 (46). These findings also appear to be independent of geographical location, with increased emergency department admissions for METH psychosis reported in the Americas (47) and the middle east (48).

\section{CHRONIC METHAMPHETAMINE PSYCHOSIS}

METH psychosis typically follows a transient course, with symptoms subsiding once the user has stopped taking the drug (3). Some consumers, however, can experience a prolonged psychosis that persists even after the drug has cleared from the body, with the majority of psychotic symptoms resolving within 1 month $(34,49)$. Some research has further indicated that METH psychosis can develop into an enduring form of psychosis. Reports have suggested that up to $30 \%$ of those with METH psychosis may have symptoms that continue up to 6 months following abstinence (49), with specific studies reporting $15-28 \%$ of patients admitted to hospital with METH psychosis needing hospitalization for more than 2-3 months following admission $(50,51)$. Additionally, others have reported that $10-$ $28 \%$ of patients with METH psychosis continued to display psychosis for more than 6 months $(35,50)$, while in another study, $28 \%$ of METH-users continued to display "schizophrenialike symptoms" 8-12 years following abstinence (52). Outside of Japan, McKetin et al. (15) reported that even abstinent METH users had a 7\% risk of experiencing psychotic symptoms and another group found that $5 \%$ of abstinent $\mathrm{METH}$-dependent users met criteria for a psychotic disorder at 3 years follow-up (53). Furthermore, METH can induce a chronic psychosis in those with no premorbid psychiatric risk factors (54), suggesting that METH use can induce persistent physiological changes consistent with psychosis that are independent to genetic and personality predispositions. It is recommended that readers examine many of the comprehensive review articles available for further information on the clinical profiles, correlates, and recovery of METH-induced psychosis (55-60). Overall, METH psychosis can result in a persistent psychotic syndrome that is resistant to spontaneous recovery, and in light of the high use of METH use globally, chronic METH psychosis will undoubtedly continue to be an issue for health-care professionals. As such, understanding the factors that subserve the neurobiology and maintenance of chronic psychosis induced by METH abuse will be important for delineating diagnostic markers and avenues for treatment.

\section{SCHIZOPHRENIA}

Schizophrenia is a severe, complex and debilitating neuropsychiatric disorder that is traditionally associated with poor treatment outcomes relative to other psychiatric disorders. It is a significantly heterogeneous disorder, with symptoms so diverse and idiosyncratic from patient to patient that the clinical profile has to be "clustered" into different domains. While there is no symptom that is sufficient for a person to be diagnosed with schizophrenia, there are particular symptoms that aid in differential diagnosis. "Positive symptoms" refer to symptoms that are usually not present but are experienced by those with schizophrenia, and include distortions in perceptions (hallucinations), false beliefs or distorted thought content (delusions), unclear or confused thinking (thought disorder), and disorganized speech. These symptoms are generally interpreted as a loss of touch with reality and are present at discrete times during "psychotic episodes," which are considered a core feature of the disorder (61). While these symptoms can also be present during remission, medication serves to suppress the severity and chronicity of these symptoms. "Negative symptoms," on the other hand, refer to symptoms or experiences that are usually absent or diminished in individuals with schizophrenia. These include social withdrawal, anhedonia, flattened affect, motor retardation, and poverty of speech $(62,63)$. Negative symptoms have a significant bearing on functional engagement and independence, with negative symptoms shown to predict the status of future functioning, employment, independence, and social contact (64).

While both positive and negative symptoms are established as core symptom dimensions and criteria for schizophrenia diagnosis in the DSM-5 (65), a third core domain reported is cognitive dysfunction. A wide range of cognitive domains appear to be compromised in schizophrenia, with many reviews and meta-analyses concluding moderate to severe deficits in general intelligence, attention, working memory, verbal learning and memory, speed of information processing, visuospatial deficits, and executive dysfunction (66-71). The cognitive deficits in schizophrenia are stable across the course of the disorder (7275 ) and are consistent between those with first episode psychosis and chronic schizophrenia (76-78). However, there is some evidence that those with earlier onset schizophrenia may have a decline in cognitive function throughout the progression of the illness (79). Furthermore, antipsychotic medication appears to have minimal positive impact, if at all, on the cognitive difficulties associated with schizophrenia (80). Executive function appears to be the most compromised and conserved cognitive deficit across patients with schizophrenia $(81,82)$, with executive deficits shown to be the most pervasive amongst older adults with schizophrenia (83) and negatively impacted by number of psychotic episodes (84). Additionally, the fact that the cognitive issues in schizophrenia are deleterious to social functioning, functional outcomes $(85,86)$, independence $(87,88)$, recovery (89), and well-being (90) has prompted the argument that cognitive dysfunction should be regarded as one of the core dimensions in the disease, particularly with respect to DSM-5 diagnostic criteria (61).

\section{THE RELATIONSHIP BETWEEN METH-INDUCED PSYCHOSIS AND SCHIZOPHRENIA}

While a subset of METH users can experience an enduring form of psychosis, there is uncertainty of the diagnostic status of chronic METH psychosis as a primary psychotic 
disorder. That is, METH-induced and other substance-induced psychoses are clearly distinguished from schizophrenia and other primary psychoses in the Diagnostic and Statistical Manual. In fact, any psychosis during the withdrawal from a substance requires the diagnosis of "substance-induced psychotic disorder" according to the Diagnostic and Statistical Manual (65) and the International Classification of Diseases, Tenth Revision (ICD-10). Diagnostic guidelines, however, become ambiguous should the psychosis persist for an extended period of time. The DSM-5 outlines that any psychosis that persist longer than 6 months should warrant the diagnosis of a primary psychotic illness (65). Indeed, a Thai study of METH abusers, who were initially hospitalized for METH psychosis found that $38.8 \%$ had been diagnosed with schizophrenia due to persistent psychosis at 5 years follow up (91), and $5.0 \%$ of Chinese patients with METH-induced psychosis had their diagnosis changed to schizophrenia (49). Longitudinal analyses have also found that $19.1 \%$ (92) to $30 \%$ (93) of patients initially admitted for amphetamine-induced psychosis had transitioned to a schizophrenia diagnosis at follow-up. Furthermore, a large study conducted over a 10 year period in the USA determined that individuals who were hospitalized for METHrelated causes had a higher risk of receiving a subsequent schizophrenia diagnosis (94). Therefore, while the potential for METH to induce an acute psychosis is well recognized, the development of an enduring-form of psychotic disorder, and its potential to transition into a primary psychotic disorder, such as schizophrenia, is not as well understood. As these studies propose that stimulant-induced psychoses represents a significant precursor to the development of more enduring forms of psychotic disorders, these findings should guide the management, early intervention and policy related to METHrelated psychoses to circumvent the progression of these conditions.

While the above findings support that METH use is associated with an enduring psychosis, there are several interpretations of the link between METH use and schizophrenia. Firstly, METH could induce schizophrenia by eliciting an underlying vulnerability/predisposition to a primary psychotic disorder. Early research on amphetamine psychosis attributed the continuation of psychotic symptoms to "latent paranoia" (95). Additionally, a growing body of literature has examined the role of genetic and environmental interactions in the development of METH psychosis, with some studies showing convergence of genetic risk factors for METH psychosis with those for schizophrenia $(58,96)$. Additionally, one study found a significant enrichment of singe nucleotide polymorphisms (SNPs) for METH psychosis risk in patients with schizophrenia (97) while another found that a family history of schizophrenia was a risk factor for the development of METH psychosis $(40,42,98)$. These findings suggest that the development of a persistent psychotic syndrome, such as schizophrenia, may be the complex interaction between a predetermined vulnerability and/or the direct effects of METH as an environmental trigger (i.e., the two hit hypothesis), and may provide an explanation as to why only a small percentage of those with METH psychosis go on to develop a persistent psychotic syndrome. More recently, however, there has been discussion surrounding the possibility that METH use could actually cause the onset of schizophrenia (54, 94, 99), potentially by inducing schizophrenia pathology. Even though this does not explain why only a percentage of users develop a persistent psychotic syndrome, both explanations suggest that METH psychosis and schizophrenia may be the same disorder on a continuum of pathology, converging with the idea that schizophrenia is a neurobiological disorder with multiple etiologies.

Alternative explanations for METH-induced psychosis may be possible. As such, it could be that METH psychosis and schizophrenia represent distinct disorders, and indeed, several researchers have proposed that METH use in isolation can produce a persistent psychotic syndrome that should be diagnosed and treated as a distinct syndrome to schizophrenia $(100,101)$. Therefore, given that any persistent psychosis beyond a 6-month period should be considered as a primary psychotic disorder, based on the current diagnostic criteria in the DSM-5, METH psychosis may be routinely misdiagnosed and treated as schizophrenia. Therefore, the diagnosis of schizophrenia secondary to METH use described in the aforementioned studies may merely reflect adherence to diagnostic protocol and may not be a true reflection of the status and prevalence of chronic METH psychosis in the general population. That is, individuals who present with METH psychosis may be diagnosed with schizophrenia, which may therefore underestimate the degree to which $\mathrm{METH}$ use results in a persistent psychotic disorder in epidemiological research studies.

Overall, there appears to be uncertainty about whether METH use causes schizophrenia or whether chronic METH psychosis represents a symptomatically distinct disorder that should be distinguished from other primary psychoses. While there appears to be similarity between the two conditions, there is limited research that has explicitly compared the behavioral and cognitive markers between the disorders. To understand the similarities and distinguishing features of METH psychosis and schizophrenia is of benefit. Not only will this assist in determining the diagnostic entity of METH psychosis, but will also help develop differential diagnostic markers for clinicians, better treatment options for long-term METH psychosis suffers, and will help to delineate common biological markers across syndromes that may initiate and maintain a persistent vulnerability to psychosis. This will enable a deeper theoretical understanding of the specific biological factors that subserve the symptoms that are commonly observed across psychotic disorders.

\section{OVERVIEW OF REVIEW}

\section{Aims}

The current review will describe and critique the literature that has compared the clinical profile of schizophrenia with (i) acute METH psychosis and (ii) chronic METH psychosis, with particular focus on positive, negative and cognitive symptoms. 
While several reviews have examined the clinical profiles, risk factors, and correlates of METH-psychosis $(55,59,60)$ and cognitive deficits associated with METH use (102-104), the aim of this study was to provide a comprehensive overview of research that has directly compared METH psychosis (acute and chronic) with schizophrenia. Furthermore, while (55) have reviewed the relationship between METH psychosis and schizophrenia, we wished to extend this review by differentiating between acute and persistent forms of METH psychosis. If the use of METH does cause a primary psychotic disorder, then the presentation and symptoms of chronic METH psychosis should match those typically reported in schizophrenia. Consequently, persistent METH psychosis could be regarded as the same diagnostic entity and could allude to similar neurobiology and etiological mechanisms. However, if METH psychosis represents a biologically and clinically distinct disorder there should be divergence in the behavioral, cognitive and biological markers between METH psychosis and schizophrenia.

\section{Inclusion Criteria}

Prior to conducting the literature search, inclusion criteria were formulated from the aims, not only to determine which studies would be suitable but to provide a unique perspective to the review and to also minimize the occurrence of methodological flaws. These included: (1) studies had to based on people, aged 16 years and older; (2) the current review focused specifically on research relating to methamphetamine (rather than amphetamine or other psychostimulants); (3) studies had examined profiles associated with METH psychosis (i.e., no studies looking at the cognitive effects of METH without psychosis); (3) studies had to have directly compared METH psychosis with schizophrenia or primary psychotic disorder (4) METH usage had to precede the presentation of psychosis in order to focus on METH-induced psychotic syndromes; (5) only original research studies were included (i.e., reviews were omitted); (6) Case studies were omitted [for a review and examination of historical case studies of METH psychosis, please see (59)].

\section{Search Approach}

To identify potential studies for inclusion in this review, the computerized databases of PubMed, PsychINFO and ScienceDirect were searched. Additionally, reference lists from retrieved articles were screened to identify omitted articles from the database search. Lastly, a Google Scholar search was conducted to ensure that no main article escaped detection in the literature search. The following search terms were used to identify potential articles: (methamphetamine psychosis OR methamphetamine-induced psychosis) AND (schizophrenia OR primary psychotic disorder) AND (negative symptoms OR positive symptoms OR psychiatric symptoms OR cognition).

\section{POSITIVE SYMPTOMS}

An overview of the design and findings of individual research studies that have directly compared METH psychosis with schizophrenia can be found in Table 1. The methodological considerations of this research are detailed in Table 2.

\section{Acute Meth Psychosis vs. Schizophrenia}

Early findings on METH induced psychosis reported hallucinations and delusions as a predominant presenting factor $(34,118)$, with later findings acknowledging that the similarities between METH psychosis and schizophrenia were largely directed toward positive symptoms. McKetin et al. (32) found that unusual thoughts, hallucinations and suspiciousness were present in one-quarter of chronic consumers of METH diagnosed with acute METH psychosis. Indeed, Bousman et al. (119) examined the variation in positive symptoms across individuals with METH psychosis. While they found three distinct sub-profiles, delusions were common amongst all individuals with METH-induced psychosis. Additional studies have also reported that METH psychosis is associated with a high prevalence of persecutory delusions, auditory and visual hallucinations, odd speech, and delusions of reference $(15,40,60,113,119-122)$.

Of studies that have directly compared acute METH psychosis with schizophrenia (Table 1), researchers have found no difference in the type and severity of positive symptoms using the Positive and Negative Syndrome Scale (PANSS) (110, 117) or the Brief Psychiatric Rating Scale (BPRS) (111). There is also research demonstrating that the longitudinal changes of positive symptoms between METH psychosis and schizophrenia are similar. For example, Hajebi et al. (117) conducted a prospective study on individuals with METHinduced psychosis and found that there was no significant difference in the severity of positive symptoms (using the PANSS) between acute METH psychosis and non-affective psychosis (e.g., schizophrenia) groups on admission, at discharge, and at 6 and 12-month follow-up. These findings suggest that the progression of positive symptoms following METH psychosis is comparable to that of schizophrenia. However, given that those with METH-induced psychosis continued to experience symptoms of psychosis following discharge, it is uncertain whether this group represents acute or chronic METH psychosis. Furthermore, it should be considered that the nonaffective psychosis group was a heterogeneous sample, consisting of participants diagnosed with schizophrenia, schizoaffective disorder and brief psychotic disorder. Collectively, these findings suggest that the positive symptoms of acute METH-induced psychosis are qualitatively and quantitatively comparable to the positive symptoms of schizophrenia, with the initial presentation of acute METH psychosis indistinguishable from schizophreniarelated psychosis (113).

Despite the considerable overlap in positive symptoms between acute METH psychosis and schizophrenia, there are several differences across both conditions. For example, Srisurapanont et al. (113) found that while there were no difference in the type and severity of positive symptoms between METH psychosis and schizophrenia, the METH psychosis group tended to have more severe hallucinations and delusions 


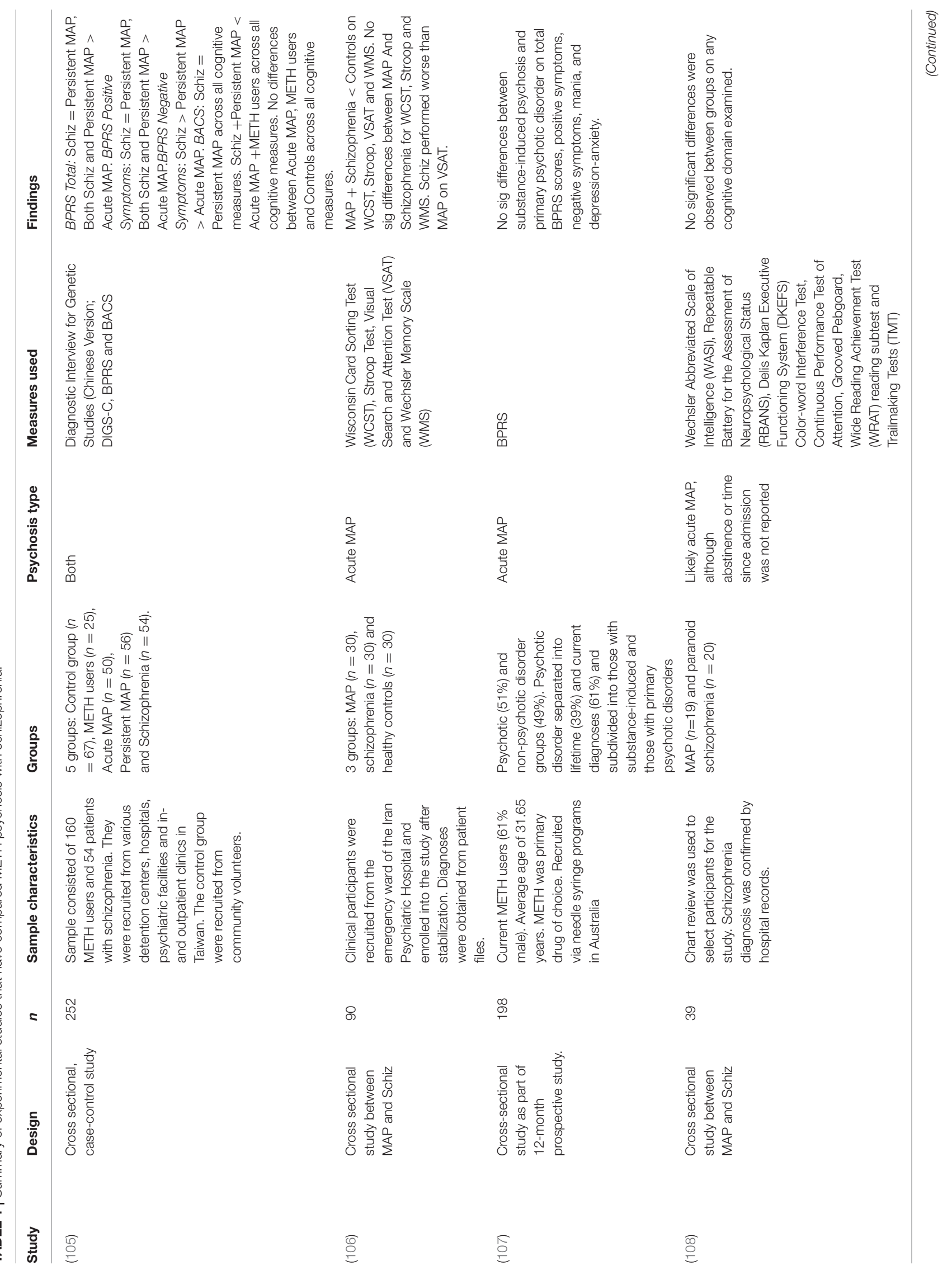




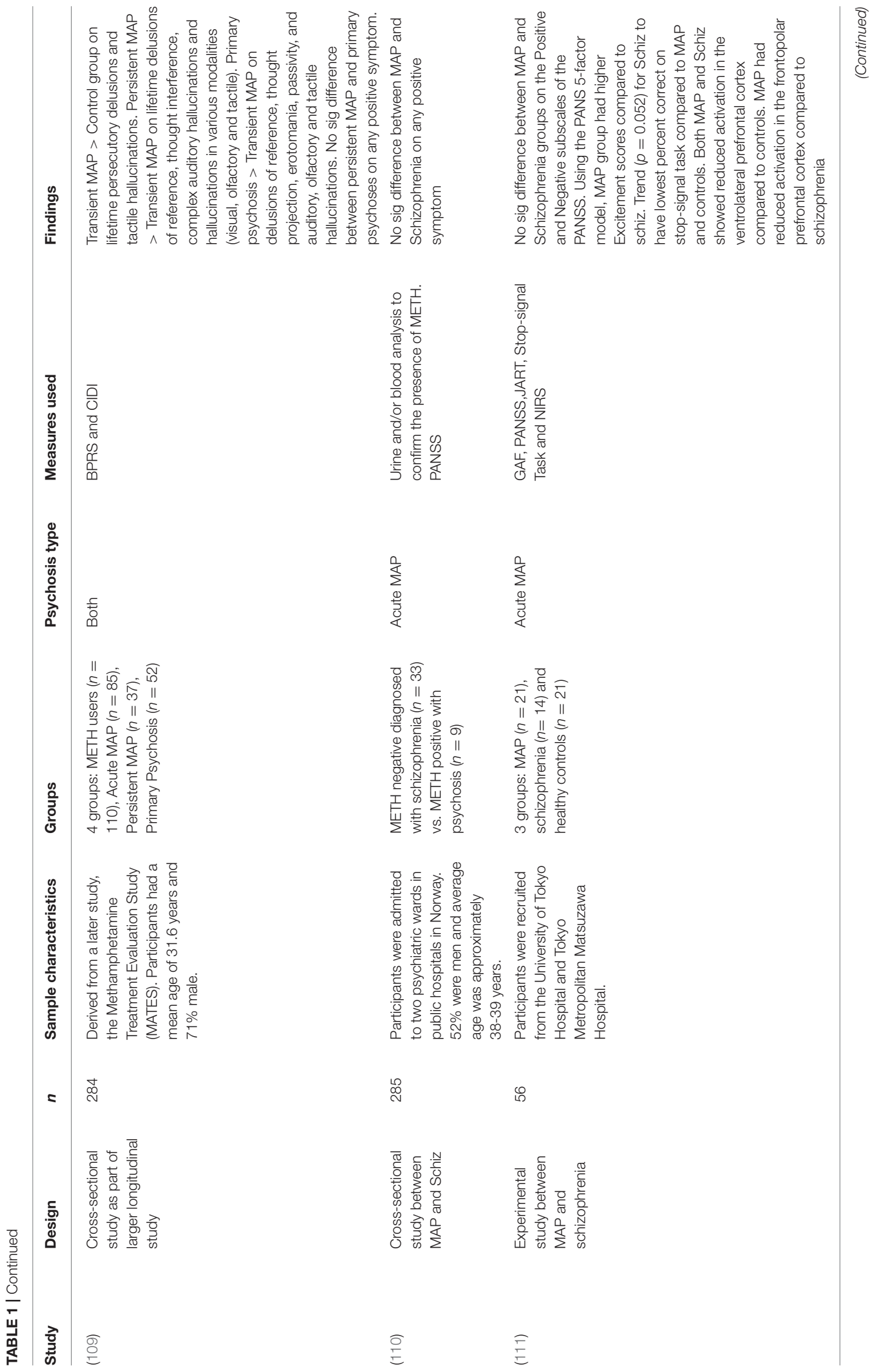




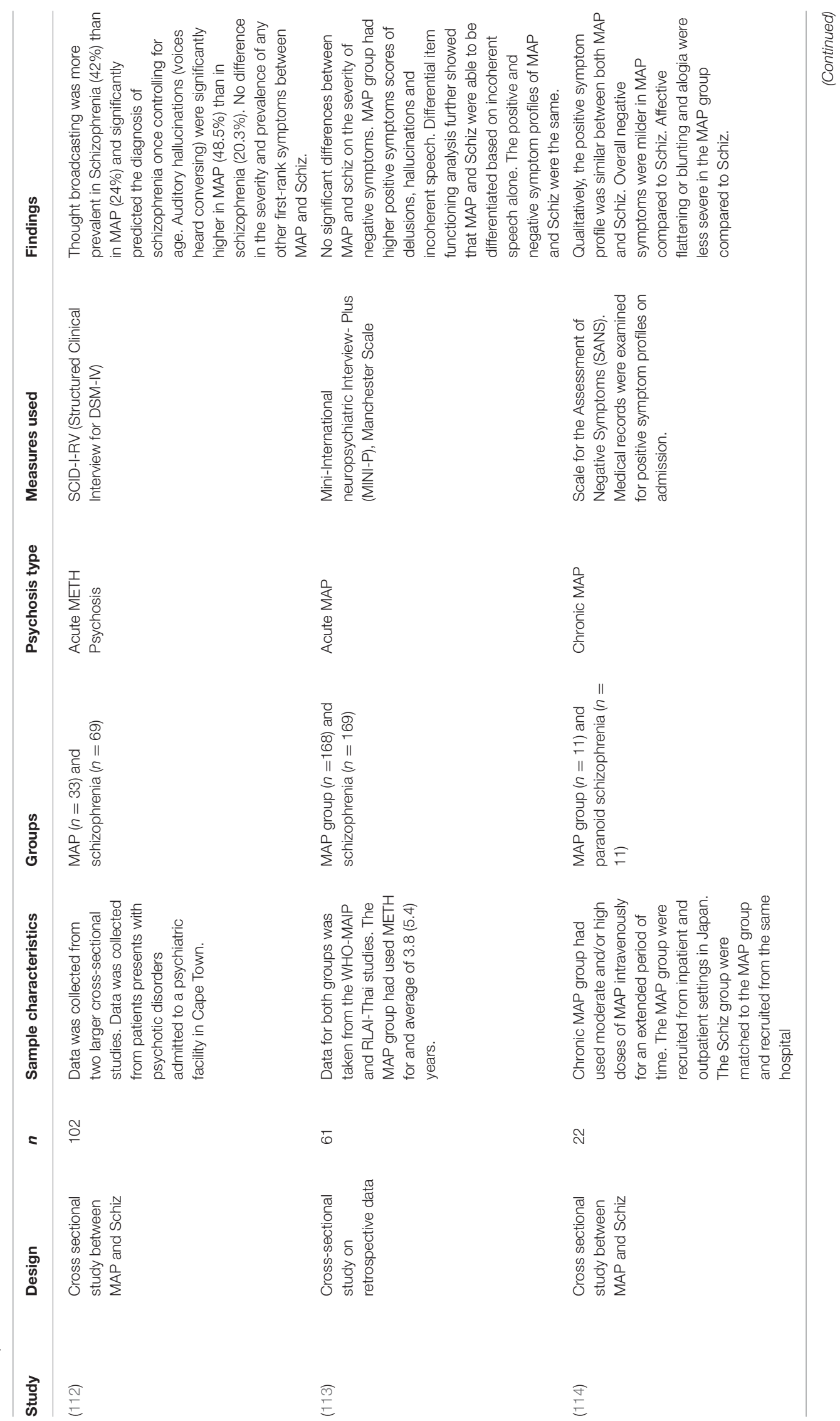




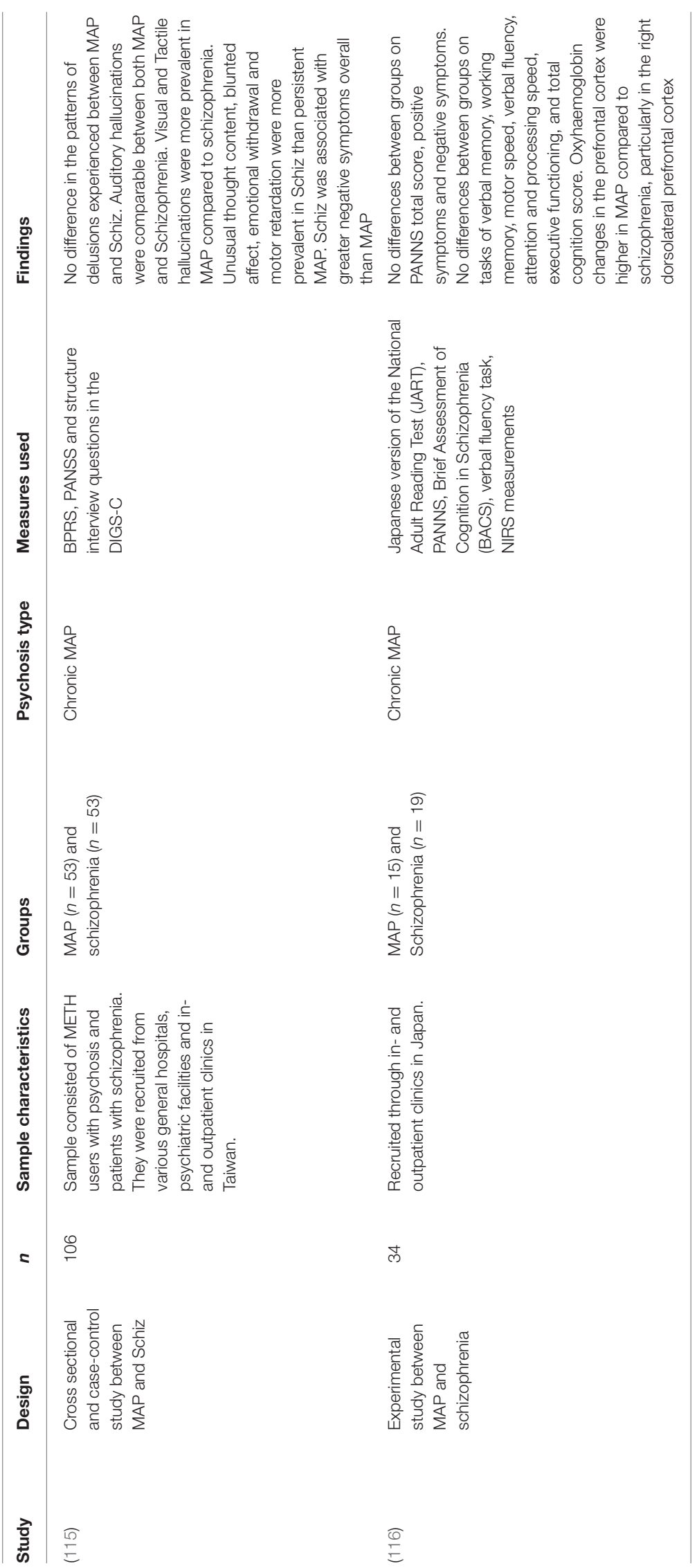




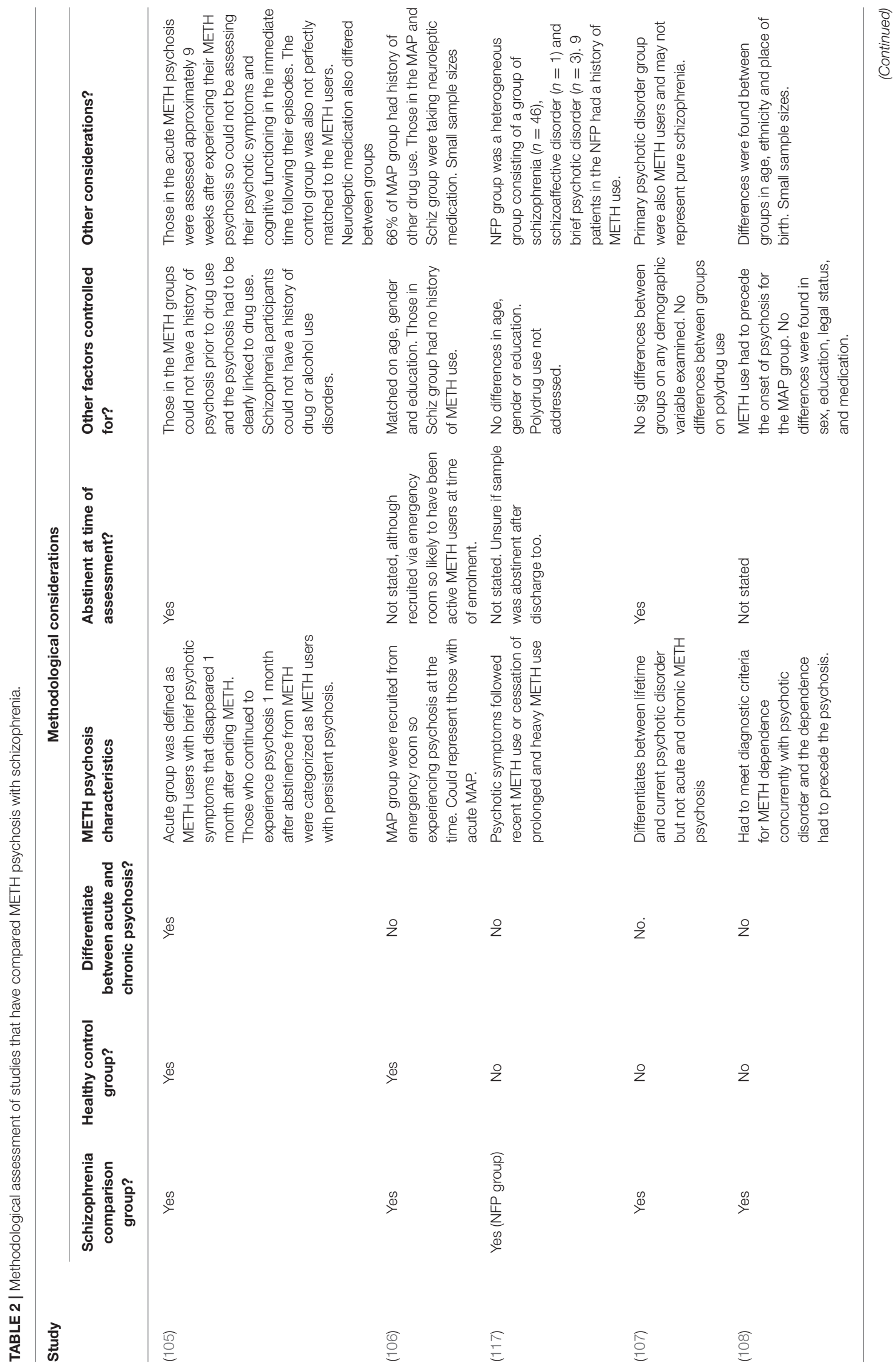




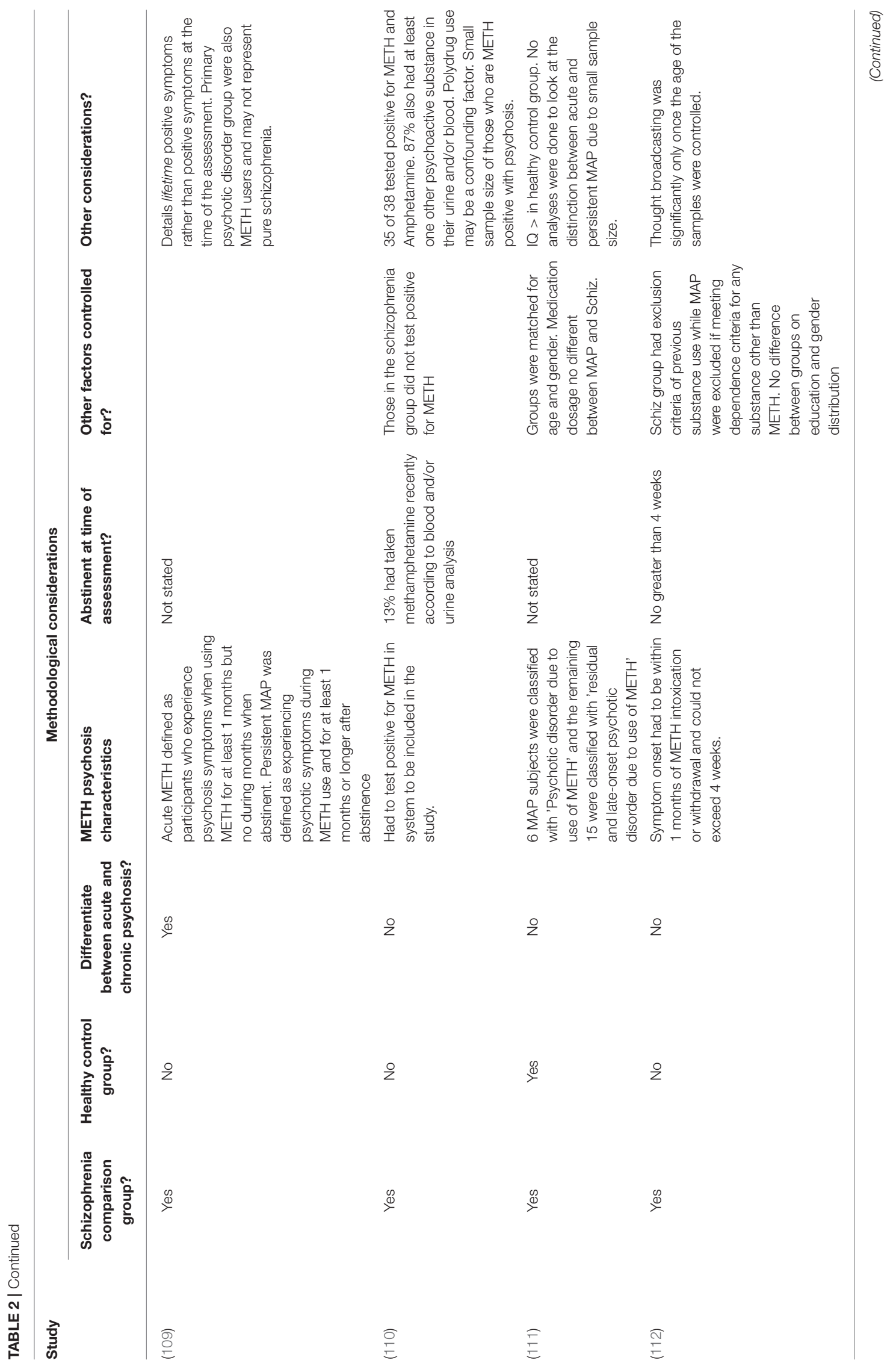




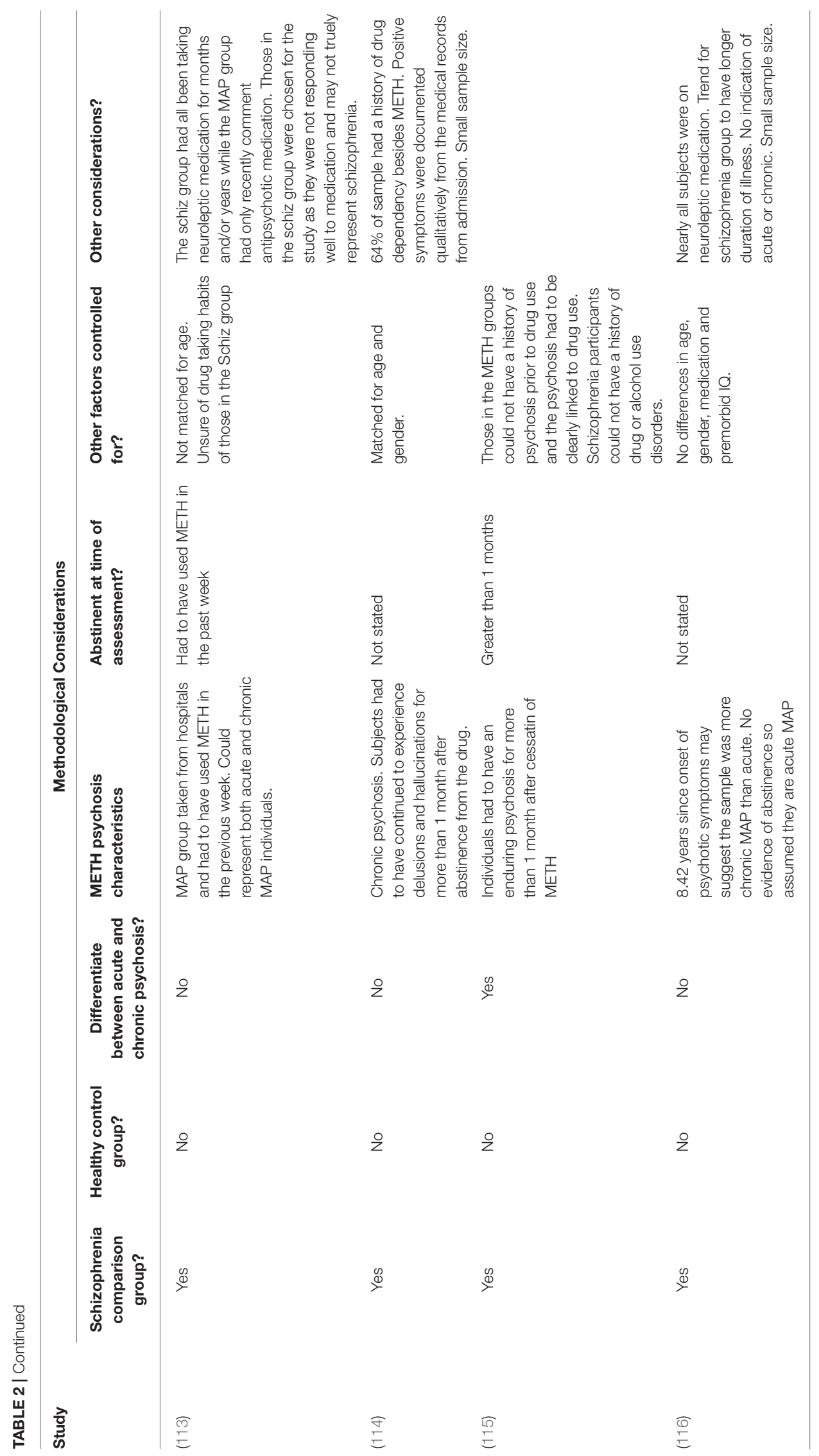


compared to schizophrenia. Further analysis revealed that incoherent speech, a distinguishing marker of thought disorder, was the only symptom to be differentially expressed between schizophrenia and METH psychosis. Thought disorder refers to disorganized thinking and is characterized by the loosening of associations and fragmented speech (123), and is suggested to be a defining and salient feature in schizophrenia (124-127). Although related to amphetamine, initial work by Bell (125) distinguished between schizophrenia and amphetamine-induced psychosis with the appearance of thought disorder, as this symptom was only seen in schizophrenic cases. Additionally, Yui et al. (127) found that while individuals with METH psychosis experienced paranoid hallucinations and delusions, the same participants did not exhibit thought disorder or disorganized speech. Therefore, the absence of thought disorder may be a discriminating feature associated with METH psychosis that can be used to differentiate this disorder from schizophrenia. However, the use of this potential discriminating feature this is currently based on indirect and inconclusive evidence, and further research is needed to determine the differentiation of thought disorder between METH psychoses and schizophrenia.

Studies that have also differentiated the types of hallucinations and delusions commonly experienced in METH psychosis and schizophrenia. Shelly et al. (112), in their examination of firstrank positive symptoms, found that acute METH psychosis and schizophrenia demonstrated comparable positive symptoms but those with acute METH psychosis showed higher frequency of auditory hallucinations (48.5\%) in comparison to schizophrenia (20.3\%). Conversely, thought broadcasting was more prevalent in the schizophrenia (42\%) group compared to METH psychosis (24\%), although this was only significant once age was controlled for in their analyses. Regardless, these findings are strengthened by the exclusion criteria of polydrug use for the METH psychosis group and METH use for the schizophrenia group. Also, the individuals in the METH psychosis group were deemed eligible if they were abstinent for no greater than 4 weeks, highlighting that this represented a true acute psychosis sample. There is also some evidence that persecutory delusions and tactile hallucinations may be specific to acute/transient METH psychosis as opposed to the chronic psychosis and schizophrenia (109), and indirect comparisons suggest that visual and tactile hallucinations appear to be more prominent in METH psychosis compared with schizophrenia $(4,125)$. Chen et al. (40) reported that 46.5 and $21.3 \%$ of their METH psychosis sample reported visual and tactile hallucinations, respectively. Additional findings have also confirmed visual hallucinations in $68.8 \%$ of $\mathrm{METH}$ abstinent individuals (128) while others have reported that visual hallucinations are the fourth most reported positive symptom in METH psychosis (120). However, visual hallucinations are typically only reported in severe cases in schizophrenia (129), with the prevalence rate ranging from 16 to $27 \%$ ( 129 , 130). Additionally, formication, a tactile hallucination where individuals believe that one's skin has been infested by bugs, is typically only reported in METH psychosis (131). Therefore, while auditory hallucinations appear to be the most common hallucination of both METH psychosis and schizophrenia, visual and tactile hallucinations appear to be more prominent in METH psychosis. However, these later findings are based on indirect comparisons and not on reliable evidence that has directly compared METH psychosis with schizophrenia.

\section{Chronic Meth Psychosis vs. Schizophrenia}

Researchers have also examined chronic METH psychosis in relation to schizophrenia. In a small study of 11 patients with chronic METH psychosis who had been abstinent from METH for more than 1 month (114) qualitatively reported that five subjects experienced visual hallucinations, seven experienced delusions of reference and persecutory delusions while all experienced auditory hallucinations. Additionally, Yamamuro et al. (116) found similar PANSS results in their experimental study examining oxygenation changes in the prefrontal cortex in acute METH psychosis and schizophrenia during a verbal fluency task. Furthermore, Wang et al. (115) examined the positive symptom profile of 52 individuals with chronic METH psychosis (who experienced psychosis and had been abstinent from METH for more than 1 month) and compared this to 53 participants with schizophrenia. They found no difference in the patterns of delusions experienced between those with chronic METH psychosis and schizophrenia and that auditory hallucinations were the most common type of hallucination experienced between groups. However, those with chronic METH psychosis significantly experienced greater visual and tactile hallucinations relative to schizophrenia while those with schizophrenia endorsed greater conceptual disorganization. This suggests that thought disorder may be specific to schizophrenia and not present in either acute or chronic METH psychoses while tactile/visual hallucinations, such as formication, may be more reflective of METH-induced psychoses. These findings are strengthened by the fact that those in the METH psychosis group could only be included if their psychosis occurred after the use of $\mathrm{METH}$, and those in the schizophrenia group could not have a history of drug use disorder, meaning that the diagnosis of each psychiatric condition was independent to the effect of several confounds.

The profiles of acute METH psychosis, persistent METH psychosis and schizophrenia have also been compared. Chen et al. (105) examined the positive symptoms experienced by those with acute METH psychosis (experienced psychosis for $<1$ month following abstinence), persistent METH psychosis (psychosis presents following abstinence from METH $>1$ month) and schizophrenia using the PANNS. Those with persistent METH psychosis and schizophrenia demonstrated comparable severity and frequency of positive symptoms, and both of these groups had PANNS scores that were significantly higher than those in the acute METH psychosis group. These findings may suggest that those with acute METH psychosis may not experience positive symptoms to the same frequency and severity as those with schizophrenia and chronic METH psychosis. However, it should be noted that those in the acute METH group were abstinent for an average of 9 weeks at the time of assessment, and therefore, the results may not truly reflect the severity of these symptoms experienced at the time of their psychotic episodes. 
Recently, McKetin et al. (109) classified 284 METH dependent participants as experiencing no current psychotic symptoms, transient psychotic symptoms when using METH, psychotic symptoms during METH use and more than 1 month abstinent (i.e., persistent METH psychosis) or as experiencing primary psychosis (i.e., schizophrenia), and examined the lifetime experience of hallucinations and delusions between groups. Relative to acute METH psychosis, it was shown that persistent METH-induced psychosis was associated with greater lifetime experiences of thought interference and delusions of reference while primary psychosis was likely to experience the same symptoms in addition to thought projection, erotomania, olfactory hallucinations and passivity (relative to acute METH psychosis). Furthermore, those with persistent METH psychosis and schizophrenia also reported reduced symptoms of visual and tactile hallucinations relative to those in the transient METH psychosis group. Importantly, the lifetime delusion and hallucination symptom profiles were not significantly different between persistent METH psychosis and primary psychosis, suggesting that the positive symptoms are comparable between the two conditions. However, it should be noted that those in the primary psychosis group were also METH dependent, suggesting that the results are not independent to drug effects, and as the authors indicate, those in the primary psychosis group may have experienced mania as opposed to schizophrenia. Furthermore, the authors examined the lifetime prevalence of psychotic symptoms, rather than those experienced during their psychotic episodes, which may explain why there was no differences between chronic psychotic syndromes. Nevertheless, these findings suggest that patients who present with greater severity and frequency of lifetime delusions and hallucinations (particularly thought interference, delusions of references and auditory hallucinations) may be at increased risk for the development of recurrent psychotic episodes or a primary psychotic disorder.

\section{NEGATIVE SYMPTOMS}

An overview of the design and findings of individual research studies that have directly compared negative symptoms in those with METH psychoses to those with schizophrenia can be found in Table 1. The methodological considerations in the examination of research that has compared symptoms between METH psychosis and schizophrenia is shown in Table 2.

\section{Acute Meth Psychosis vs. Schizophrenia}

While stimulant-induced psychotic disorders have been predominantly characterized by positive symptoms, negative symptoms such as flat affect, social withdrawal, apathy, loss of drive, anhedonia and poverty of speech have also been reported in METH psychosis samples $(4,40,113,123,132)$. Srisurapanont et al. (113) showed no difference between METH psychosis and schizophrenia on measures of psychomotor retardation, flattened affect and poverty of speech using the Manchester scale, while other researchers have found no significant differences between METH psychosis and schizophrenia using the BPRS (107) or the PANSS (111).
However, some researchers have shown differences in the severity of negative symptoms experienced between acute METH psychosis and schizophrenia. For example, Hajebi et al. (117) found that on admission to hospital, those with nonaffective psychosis had more severe negative symptoms than those with acute METH-psychosis. Furthermore, while the severity of negative symptoms had improved for both groups upon discharge, the non-affective psychosis group continued to maintain increased severity of negative symptoms relative to the acute METH-psychosis group. There is also indirect evidence that negative symptoms are less severe in acute METH psychosis compared to schizophrenia. Negative symptoms are common in schizophrenia, with negative symptoms considered a central feature of its phenomenology and diagnostic criteria $(133,134)$. Indeed, $58 \%$ of individuals with schizophrenia experience negative symptoms (135), with $50-90 \%$ of those with schizophrenia displaying negative symptoms in first-episode psychosis (136). On the other hand (132) found that only $25 \%$ of individuals hospitalized with METH psychosis exhibited negative symptoms while (122) similarly found that only $21.4 \%$ of their sample met criteria for negative symptoms in a clinical interview using the MINI-plus. While these lower prevalence rates may be attributable to limited research in the area, specifically with respect to inclusion and appropriate assessment of negative symptoms in research studies, these findings suggest that negative symptoms may be experienced at a considerably lower rate in acute METH psychosis compared with schizophrenia.

\section{Chronic Meth Psychosis vs. Schizophrenia}

Previous research has explicitly compared the negative symptoms between chronic METH psychosis and schizophrenia. Tomiyama (114) examined the experience of negative symptoms between 11 participants with chronic METH psychosis and 11 participants with schizophrenia using the Scale for the Assessment of Negative Symptoms (SANS). They found that negative symptoms were milder in chronic METH psychosis overall when compared to schizophrenia. When examining the individual symptoms, however, they found that ratings of avolition-apathy, anhedoniaasociality, and attentional impairment were similar between both groups, but those with schizophrenia demonstrated elevated symptoms of affective flattening and alogia. Additionally, Wang et al. (115) found that schizophrenia was associated with greater frequency and severity of negative symptoms compared to those with chronic METH psychosis. Specifically, those with schizophrenia demonstrated elevated scores for blunted affect, emotional withdrawal and motor retardation. Furthermore, in differentiating between acute and chronic METH psychosis with schizophrenia (105), using the BPRS, found that those with schizophrenia demonstrated the greatest severity of negative symptoms compared to those with acute and chronic METH psychosis, but the negative symptoms demonstrated by the chronic METH psychosis group were significantly greater than those in the acute METH group. Therefore, even though negative symptoms have been reported in both schizophrenia and METH psychosis, schizophrenia appears to be associated with greater prevalence and severity of negative symptoms compared to METH psychoses. 


\section{COGNITIVE SYMPTOMS}

An overview of the design and findings of individual research studies that have directly compared the cognitive symptoms associated with METH psychosis to those of schizophrenia can be found in Table 1. The methodological considerations in the examination of research that has compared symptoms between METH psychosis and schizophrenia is shown in Table 2.

\section{Acute Meth Psychosis vs. Schizophrenia}

Recent work has examined the prevalence and severity of cognitive dysfunction following acute METH psychosis in comparison with schizophrenia. Jacobs et al. (108) in an exploratory cross-sectional study, compared the cognitive profile of individuals hospitalized with METH psychosis with patients with paranoid schizophrenia across eight cognitive domains, including premorbid intellectual ability, learning and memory, executive functioning, general intellectual functioning, attention and concentration, motor abilities together with non-verbal and verbal skills. They found no significant differences between the two groups in any cognitive domain examined, suggesting that both METH psychosis and schizophrenia may have similar cognitive profiles and may therefore share underlying brain pathology, particularly with respect to dysfunction of the frontal and temporal lobes. However, there are several limitations to these findings. Firstly, the groups had small sample sizes. Secondly, there were between-group differences in age, ethnicity and place of birth between those with METH psychosis and schizophrenia and as such, these factors may have been confounds in the study. Additionally, it was not known how long the sample had been abstinent from METH nor was it reported how long the METH psychosis sample had been taking METH prior to their participation in the study. Regardless, this initial study suggested that METH psychosis may show cognitive deficits, similar to those typically reported in schizophrenia.

Ezzatpanah et al. (106) further compared cognitive function in individuals with METH-induced psychosis and schizophrenia to healthy controls, with all subjects matched for age, sex and education. They found that both METH psychosis and schizophrenia were characterized by reduced performance on all cognitive tasks examined when compared to healthy controls, and there were no significant differences in the performance of those with acute METH psychosis and schizophrenia across tasks of memory, sustained attention, selective attention and executive functioning. Specifically, METH psychosis and schizophrenia groups demonstrated difficulty in inhibiting, manipulating and suppressing information, together with difficulties learning and retaining verbal information over time. These findings indicate that both disorders may be characterized by comparable deficits of cognition mediated by the temporal and frontal lobes, specifically the prefrontal cortex, and further extends the findings of Jacobs et al. (108) that both METH psychosis and schizophrenia may be the product of similar pattern of brain pathology. While both these studies were hampered by small sample sizes, these similar findings are strengthened by the fact that these two studies were derived from different cultural samples - American (108) and Iranian (106)-and through the use of distinct cognitive measures. However, despite the overwhelming similarities in cognitive dysfunction between METH psychosis and schizophrenia (106) found that individuals with schizophrenia and METH psychosis demonstrated difficulties with sustained visual attention compared to controls, yet those with schizophrenia performed worse than subjects with acute METH psychosis. As selective visual attention is primarily correlated with the parietal cortex (137), these findings indicate that dysfunction of the parietal cortex may be more pronounced in schizophrenia than acute METH psychosis.

\section{Chronic Meth Psychosis vs. Schizophrenia}

The above studies were based on recent abstinent METH users and may not be generalizable to those with chronic METH psychosis. However, there is emerging evidence of similarities between cognitive symptoms in persistent METH psychosis and schizophrenia in the literature. For example, (116) examined individuals with METH psychosis and schizophrenia on a verbal fluency tasks while they had their brain blood oxygenation levels recorded using Functional Near-Infrared Spectroscopy (NIRS). They also had their cognitive ability measured using the Brief Assessment of Cognition in Schizophrenia (BASC). They found there was no difference between those with METH-psychosis and schizophrenia on tasks of verbal memory, working memory, motor speed, verbal fluency, attention, speed of information processing, executive functioning and total cognitive ability. However, oxyhaemaoglobin changes in the prefrontal cortex were higher in the METH psychosis group compared to schizophrenia, particularly in the right dorsolateral prefrontal cortex. This suggests that while the cognitive ability may be similarly perturbed across METH psychosis and schizophrenia, there are biological changes that may be used to distinguish between the two conditions. However, a significant limitation in this study is that the length of abstinence for the METH psychosis group was not stated. Given that the sample had been 8.42 years since the onset of psychotic symptoms (average of 2.5 hospitalizations and 8.42 months of hospitalization), the sample likely reflects a more persistent METH psychosis, and the researchers referred to the sample as "methamphetamine-induced psychotic disorder." However, in the absence of abstinence information, it is uncertain whether these findings are applicable to acute or chronic METH psychosis, or the sample could reflect a blended representation.

More recent research has shown that cognitive dysfunction is specific to the persistent form of METH psychosis rather than acute METH psychosis. For example, Chen et al. (105) conducted a well-designed cross-sectional study on healthy controls, METH users without psychosis, METH users with acute psychosis (METH users who had psychotic symptoms that dissipated within 1 month following abstinence), METH users with persistent psychosis (psychosis greater than 1 month), and individuals with schizophrenia. They found that METH users with persistent psychosis performed comparably to those with schizophrenia across all cognitive domains, with both these groups performing worse than the other acute METH psychosis, METH users without psychosis and control groups. These findings extend the findings of Jacobs et al. (108) and Ezzatpanah et al. (106) by clearly distinguishing between METH users with 
acute and persistent psychoses, suggesting that schizophrenia and only persistent psychosis secondary to METH use are associated with similar cognitive profiles. This may indicate that the samples used in previous studies could represent a mixture of both acute and persistent METH psychoses. These findings therefore suggest that cognitive dysfunction may develop in individuals who originally had acute symptoms that endured over time, likely as a secondary consequence to neuropathological changes that coincide with abstinence. Altogether, these findings indicate that chronic METH-induced psychosis is associated with brain changes that may be carefully distinguished from the changes concomitant with METH use and acute METH psychosis.

\section{METHODOLOGICAL LIMITATIONS AND CONSIDERATIONS}

An overview of the methodological considerations in the examination of research that has compared symptoms between METH psychosis and schizophrenia is shown in Table 2. One of the biggest limitations with METH psychosis research is that little effort is made to distinguish between those with acute and chronic METH psychosis, with the majority of the findings portraying a blended representation of all types. Indeed, the majority of studies failed to report the length of time of abstinence from METH at the time of the assessment. For the purpose of this review, therefore, we considered these studies to represent acute METH psychosis studies as there was no evidence to suggest that these samples had been abstinent for long enough to be considered to be representative of chronic METH psychosis [ $>1$ month abstinence according to published papers, e.g., (105)]. Additionally, few studies indicate whether their samples are abstinent at the time of the assessment. Taken together, the findings presented in these papers may not be generalizable to samples of chronic METH psychosis, as it is uncertain whether these behavioral outcomes are referable to the direct effects of METH, acute METH psychosis or persistent METH psychosis.

In keeping with this limitation, some studies implement diagnostic criteria for chronic METH psychosis that is distinct by those provided by the DSM-5. That is, these studies typically categorize those who continue to experience psychosis after discontinuing METH for more than 1 month as those with persistent METH psychosis. According to the DSM, however, these patients should be diagnosed with a primary psychotic disorder, and some studies adhere to these guidelines. Consequently, individuals with chronic METH psychosis may be categorized as participants with schizophrenia. There are several implications to this procedure. Firstly, chronic METH psychosis may be underreported across scientific literature. Secondly, the inappropriate allocation of participants to treatment conditions precludes the examination of distinct clinical and symptom profiles between conditions given the significant heterogeneity across various outcome measures. Furthermore, inconsistency in sample characteristics hinders the ability to pool data and conclusions across research studies. Indeed, it is worth noting that other researchers have proposed similar concerns about this approach to METH psychosis research (138). Given that only
METH users with a persistent METH psychosis syndrome appear to display the cognitive dysfunction typically associated with schizophrenia (105), it is possible that the differences in positive, negative and cognitive symptoms reported in additional studies may refer only to acute METH psychosis. It will be important for future research to examine the effect of persistent METH psychosis and how this relates to the behavioral, cognitive and biological changes typically reported in schizophrenia in order to elucidate whether chronic METH psychosis represents a distinct psychotic disorder and to differentiate the clinical profiles of acute vs. chronic psychosis forms.

There are additional limitations to this field of research that should be addressed. Firstly, many studies are of low sample size, meaning that many of the similarities between METH psychosis and schizophrenia may be due to low statistical power to detect significant difference between groups. Secondly, many studies do not control for polydrug use, meaning that the symptoms of psychosis may not be exclusively attributed to METH administration. Thirdly, studies do not actively control for the effect of psychotropic medication, particularly given that this impacts on the presentation of behavioral symptoms. Additionally, many studies are reliant on hospitalized samples, which are likely concomitant with more severe psychosis than non-treatment-seeking individuals with METH psychosis in the community. Lastly, many studies compare METH psychosis to schizophrenia using screening or brief assessment tools. A significant limitation of these scales is that they do not differentiate the qualitative nature of the hallucinations or delusions experienced, as they quantify the status of positive symptoms with a total score, meaning that these scales may be unable to detect differences that may differentiate these conditions. The use of such tools may explain why research studies produce such contrasting, and at times conflicting, clinical profiles. For example, the positive symptoms associated with METH psychosis and schizophrenia using the PANSS and BPRS are comparable, but examination using more indepth tools, such as the Manchester Scale, revealed differences in the type of positive symptoms experienced between groups.

\section{SUMMARY AND CONCLUSIONS}

A comparison of the positive, negative and cognitive symptoms between schizophrenia and acute/chronic METH psychosis is detailed in Figure 1. Research has shown both similarities and differences in the positive, negative and cognitive symptoms between METH-induced psychosis and schizophrenia. There appears to be a high degree of concordance in the type, prevalence and severity of positive symptoms between METHinduced psychosis and schizophrenia, confirming that it would be difficult to distinguish between the two conditions in the clinical setting based on the positive symptoms alone. However, while auditory hallucinations appear to be the most common hallucination reported in METH psychosis (acute and chronic) and schizophrenia, visual and tactile hallucinations appear to be more prominent in acute/transient 


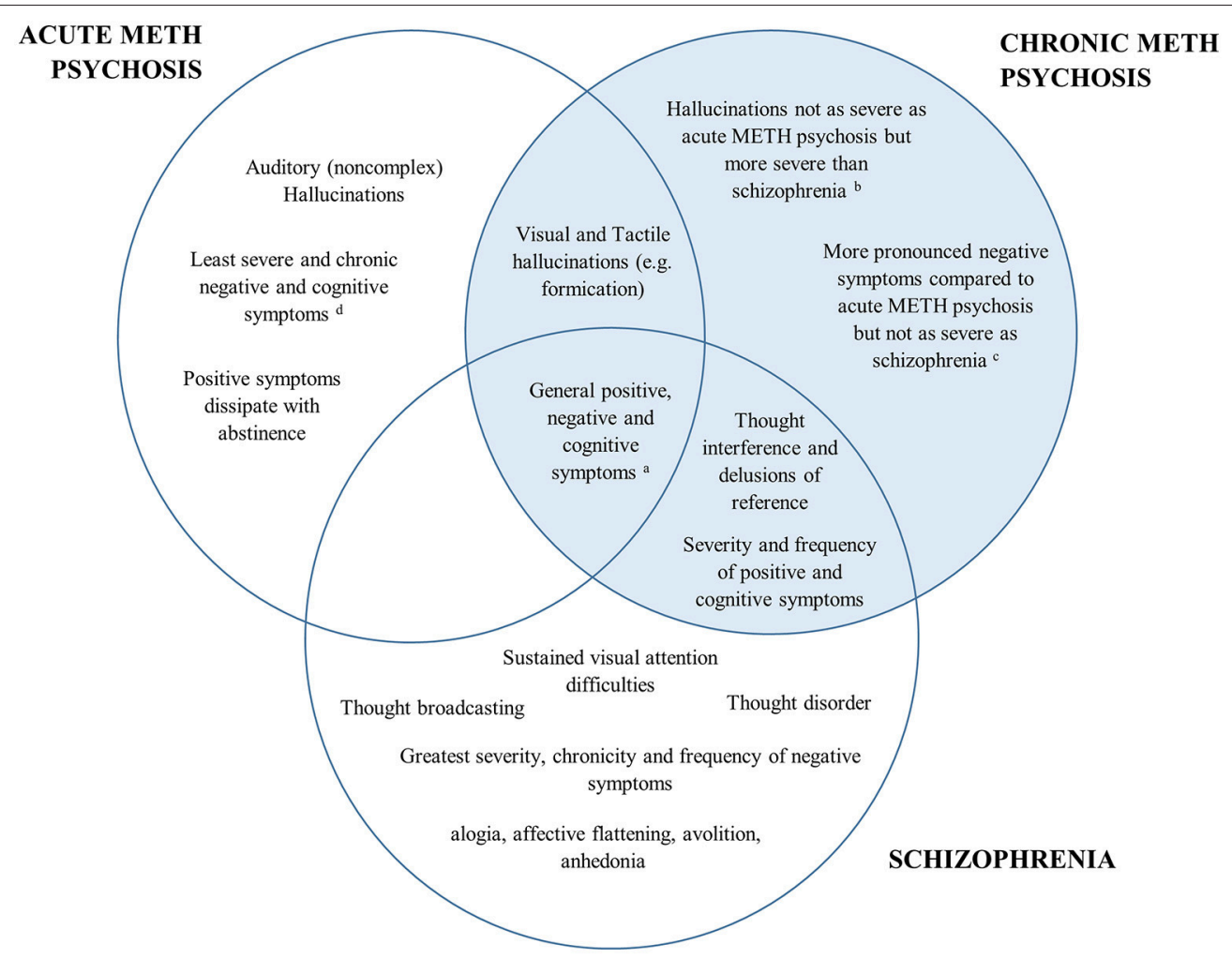

FIGURE 1 | Venn diagram of the overlap in psychiatric and cognitive symptomatology between acute METH psychosis, chronic METH psychosis, and schizophrenia. The left represents symptoms specific to acute METH psychosis, the right (highlighted blue) represents the symptoms and profile specific to chronic METH psychosis, while the bottom highlights those associated specifically with a schizophrenia profile. Symptoms that are common across disorders are shown in the overlap. ${ }^{\text {Aall }}$ conditions demonstrate some degree of positive, negative and cognitive symptomatology according the specific syndrome scales (e.g., Brief Psychiatric Rating Scale or the Positive and Negative Severity Scale). ${ }^{b}$ Visual and tactile hallucinations: Acute METH psychosis > Chronic METH psychosis > Schizophrenia ${ }^{\mathrm{c}}$ Severity of negative symptoms: Schizophrenia > Chronic METH psychosis > Acute METH psychosis. ${ }^{d}$ Cognition: Schizophrenia $=$ Chronic METH psychosis $>$ Acute METH psychosis.

METH psychosis, with thought disorder the most pronounced symptom in schizophrenia. While negative symptoms occur in both conditions, some research has indicated that there are differences in the type, severity and progression of negative symptoms throughout both conditions, with METH psychosis associated with reduced frequency and severity of several negative markers, such as flattened affect (although chronic psychosis is associated with worse negative symptoms than acute METH psychosis). Lastly, from a cognitive perspective, most cognitive domains appear to be similarly perturbed across METH psychosis and schizophrenia. However, recent findings have highlighted that some functions subserved by the parietal cortex, such as selective visual attention, may be more pronounced in schizophrenia that acute METH psychosis, and that cognitive dysfunction may be specifically comparable to schizophrenia for those with chronic METH psychosis.

Overall, while there is considerable overlap in the behavioral and cognitive symptoms between acute METH psychosis and schizophrenia, research has shown that there are unique aspects to each condition. While both disorders may be characterized by common underlying biological pathologies and phenotypes, acute METH psychosis could represent a distinct psychotic disorder to schizophrenia and may be clinically distinguished from a primary psychotic disorder based on distinct behavioral and cognitive sequelae. On the other hand, preliminary evidence suggests that chronic METH psychosis may be clinically similar to that of primary psychotic disorders, particularly with respect to positive and cognitive symptomatology. However, given the number of limitations evident in the available studies, particularly with respective to the paucity of experimental designs that differentiate between acute and chronic forms of METH psychosis, there is insufficient evidence to conclude whether chronic METH psychosis is clinically distinct from schizophrenia.

Nevertheless, these findings may have implications for the longer-term management and treatment of such conditions. For example, concerning the management of acute METH psychosis, symptoms will resolve with abstinence from METH and with the appropriate management of withdrawal. Therefore, for the most part, long-term pharmacological interventions for acute METH psychoses would not be needed or beneficial (139). However, given the similarity in symptoms between 
persistent METH psychosis and schizophrenia, second generation antipsychotic medicines, such as risperidone and olanzapine, may be appropriate intervention strategies. While first-generation anti-psychotics (i.e., haloperidol) may useful for the management of schizophrenia, and therefore, persistent METH psychosis, such medicines are at elevated risk of causing extrapyramidal symptoms in individuals with METH induced psychosis, and should therefore be used carefully $(56,140)$. However, these suggestions are not clinical recommendations and should be further examined using large randomized clinical trials so that clinical guidelines on the appropriate treatment of these conditions can be developed.

\section{REFERENCES}

1. Anglin MD, Burke C, Perrochet B, Stamper E, Dawud-Noursi S. History of the methamphetamine problem. J Psychoactive Drugs (2000) 32:137-41. doi: 10.1080/02791072.2000.10400221

2. Hart CL, Marvin CB, Silver R, Smith EE. Is cognitive functioning impaired in methamphetamine users? A critical review. Neuropsychopharmacology (2012) 37:586-608. doi: 10.1038/npp.2011.276

3. Meredith CW, Jaffe C, Ang-Lee K, Saxon AJ. Implications of chronic methamphetamine use: a literature review. Harv Rev Psychiatry (2005) 13:141-54. doi: 10.1080/10673220591003605

4. Zorick TS, Rad D, Rim C, Tsuang J. An overview of methamphetamineinduced psychotic syndromes. Addict Disord Their Treatm. (2008) 7:143-56. doi: 10.1097/ADT.0b013e318066d5e 0

5. Homer BD, Solomon TM, Moeller RW, Mascia A, DeRaleau L, Halkitis PN. Methamphetamine abuse and impairment of social functioning: a review of the underlying neurophysiological causes and behavioral implications. Psychol Bull. (2008) 134:301-10. doi: 10.1037/0033-2909.134.2.301

6. Chuang L-W, Karoum F, Jed Wyatt R. Different effects of behaviorally equipotent doses of amphetamine and methamphetamine on brain biogenic amines: specific increase of phenylethylamine by amphetamine. Euro $J$ Pharmacol. (1982) 81:385-92. doi: 10.1016/0014-2999(82)90103-0

7. Fleckenstein AE, Volz TJ, Riddle EL, Gibb JW, Hanson GR. New insights into the mechanism of action of amphetamines. Annu Rev Pharmacol Toxicol. (2007) 47:681-98. doi: 10.1146/annurev.pharmtox.47.120505.105140

8. Freye E. Pharmacology of methamphetamine. In: Fry E, Levi J, Editors. Pharmacology and Abuse of Cocaine, Amphetamines, Ecstasy and Related Designer Drugs. Dordrecht: Springer (2010). pp. 119-24. doi: 10.1007/978-90-481-2448-0

9. Izawa J, Yamanashi K, Asakura T, Misu Y, Goshima Y. Differential effects of methamphetamine and cocaine on behavior and extracellular levels of dopamine and 3,4-dihydroxyphenylalanine in the nucleus accumbens of conscious rats. Eur J Pharmacol. (2006) 549:84-90. doi: 10.1016/j.ejphar.2006.08.031

10. Weisheit R. Methamphetamine: Its History, Pharmacology and Treatment. Minnesota: Hazelden Publishing (2013).

11. Elliott JM, Beveridge TJ. Psychostimulants and monoamine transporters: upsetting the balance. Curr Opin Pharmacol. (2005) 5:94-100. doi: 10.1016/j.coph.2004.09.005

12. Pierce RC, Kalivas PW. A circuitry model of the expression of behavioral sensitization to amphetamine-like psychostimulants. Brain Res Brain Res Rev. (1997) 25:192-216.

13. UNODC. World Drug Report. New York, NY: UNODC (2009).

14. UNODC. Global Amphetamine-type Stimulant Assessment: Amphetamine and Ecstasy. New York, NY: UNODC (2011).

15. McKetin R, Lubman DI, Baker AL, Dawe S, Ali RL. Dose-related psychotic symptoms in chronic methamphetamine users: evidence from a prospective longitudinal study. JAMA Psychiatry (2013) 70:319-24. doi: 10.1001/jamapsychiatry.2013.283

\section{AUTHOR CONTRIBUTIONS}

TW and JC designed the review. TW conducted the review; TW wrote the initial version of the manuscript with subsequent contribution from JC.

\section{ACKNOWLEDGMENTS}

TW was in receipt of an Australian Postgraduate Award (APA) and would like to acknowledge the support of Macquarie University in the form of the Psychology Department Higher Degree Research Grant.

16. UNODC World Drug Report. New York, NY: UNODC (2013).

17. UNODC. World Drug Report. from New York, NY: UNODC (2014).

18. UNODC. World Drug Report. New York, NY: UNODC (2003).

19. UNODC. Global Synthetic Drugs Assessment: Amphetamine-Type Stimulants and New Psychoactive Substances. New York, NY: UNODC (2014).

20. SAMHSA. National Admissions to Substance Abuse Treatment Service, Treatment Episode Data Set (TEDS): 1994-2004. Rockville, MD: Office of Applied Studies (2006).

21. SAMHSA. Reults from the 2007 National Survey on Drug Use and Health: National Findings. Rockville, MD: Office of Applied Studies (2008).

22. SAMHSA. Treatment Episode Data Set (TEDS): 2004-2014. National Admissions to Substance Abuse Treatment Services. No. BHSIS Series S-84, HHS Publication No. SMA (2016). pp. 16-4986.

23. AIHW. Alcohol and Other Drug Treatment Services in Australia 2014-15. Canberra, ACT: AIHW (2016).

24. AIHW. National Hospital Morbidity Database: Principal Diagnosis Data Cubes for 1993-94 to 2012-13. Canberra, ACT: AIHW (2016).

25. QLDHealth. Queensland Methamphetamine Paper. Brisbane, QLD: QLDHealth (2017).

26. Cook CE, Jeffcoat AR, Hill JM, Pugh DE, Patetta PK, Sadler BM, et al. Pharmacokinetics of methamphetamine self-administered to human subjects by smoking S-(+)-methamphetamine hydrochloride. Drug Metab Disposition (1993) 21:717-23.

27. Cruickshank CC, Dyer KR. A review of the clinical pharmacology of methamphetamine. Addiction (2009) 104:1085-99. doi: 10.1111/j.1360-0443.2009.02564.x

28. Topp L, Degenhardt L, Kaye S, Darke S. The emergence of potent forms of methamphetamine in Sydney, Australia: a case study of the IDRS as a strategic early warning system. Drug Alcohol Rev. (2002) 21:341-8. doi: 10.1080/0959523021000023199

29. AIHW. National Drug Strategy Household Survey Report. Canberra, ACT: AIHW (2010).

30. AIHW. National Drug Strategy Household Survey Report. Canberra: ACT: AIHW (2013).

31. Bramness J, Gundersen O, Guterstam J, Rognli E, Konstenius M, Loberg $\mathrm{E}-\mathrm{M}$, et al. Amphetamine-induced psychosis - a separate diagnostic entity or primary psychosis triggered in the vulnerable? BMC Psychiatry (2012) 12:221. doi: 10.1186/1471-244X-12-221

32. McKetin R, McLaren J, Lubman DI, Hides L. The prevalence of psychotic symptoms among methamphetamine users. Addiction (2006) 101:1473-8. doi: 10.1111/j.1360-0443.2006.01496.x

33. Zweben JE, Cohen JB, Christian D, Galloway GP, Salinardi M, Parent D, et al. Psychiatric symptoms in methamphetamine users. Am J Addict. (2004) 13:181-90. doi: 10.1080/10550490490436055

34. Sato M. A lasting vulnerability to psychosis in patients with previous methamphetamine psychosis. Ann N Y Acad Sci. (1992) 654:160-70.

35. Ujike $\mathrm{H}$, Sato $\mathrm{M}$. Clinical features of sensitization to methamphetamine observed in patients with methamphetamine dependence and psychosis. Ann N Y Acad Sci. (2004) 1025:279-87. doi: 10.1196/annals.1316.035 
36. Salo R, Fassbender C, Iosif AM, Ursu S, Leamon MH, Carter C. Predictors of methamphetamine psychosis: history of ADHD-relevant childhood behaviors and drug exposure. Psychiatry Res. (2013) 210:529-35. doi: 10.1016/j.psychres.2013.06.030

37. Lecomte T, Dumais A, Dugré JR, Potvin S. The prevalence of substanceinduced psychotic disorder in methamphetamine misusers: a meta-analysis. Psychiatry Res. (2018) 268:189-92. doi: 10.1016/j.psychres.2018.05.033

38. Mahoney J, Hawkins R, De La Garza R, Kalechstein A, Newton T. Relationship between gender and psychotic symptoms in cocaine-dependent and methamphetamine-dependent participants. Gend Med. (2010) 7:414-21. doi: 10.1016/j.genm.2010.09.003

39. McKetin R, Hickey K, Devlin K, Lawrence K. The risk of psychotic symptoms associated with recreational methamphetamine use. Drug Alcohol Rev. (2010) 29:358-63. doi: 10.1111/j.1465-3362.2009.00160.x

40. Chen CK, Lin SK, Sham PC, Ball D, Loh EW, Hsiao CC, et al. Pre-morbid characteristics and co-morbidity of methamphetamine users with and without psychosis. Psychol Med. (2003) 33:1407-14. doi: 10.1017/S0033291703008353

41. McKetin R, Kelly E, McLaren J. The relationship between crystalline methamphetamine use and methamphetamine dependence. Drug Alcohol Depend. (2006) 85:198-204. doi: 10.1016/j.drugalcdep.2006.04.007

42. Matsumoto T, Kamijo A, Miyakawa T, Endo K, Yabana T, Kishimoto H. Methamphetamine in Japan: the consequences of methamphetamine abuse as a function of route of administration. Addiction (2002) 97:809-817. doi: 10.1046/j.1360-0443.2002.00143.x

43. Lappin JM, Roxburgh A, Kaye S, Chalmers J, Sara G, Dobbins T, et al. Increased prevalence of self-reported psychotic illness predicted by crystal methamphetamine use: evidence from a high-risk population. Int J Drug Policy (2016) 38:16-20. doi: 10.1016/j.drugpo.2016.10.018

44. Farrell M, Boys A, Bebbington P, Brugha T, Coid J, Jenkins R, et al. Psychosis and drug dependence: results from a national survey of prisoners. $\mathrm{Br} J$ Psychiatry (2002) 181:393-8. doi: 10.1192/bjp.181.5.393

45. McKetin R. Estimating the Number of Regular and Dependent Methamphetamine Users in Australia. Sydney: National Drug and Alcohol Research Centre (2005).

46. Degenhardt L, Sara G, McKetin R, Roxburgh A, Dobbins T, Farrell M, et al. Crystalline methamphetamine use and methamphetamine-related harms in Australia. Drug Alcohol Rev. (2017) 36:160-70. doi: 10.1111/dar.12426

47. Richards JR, Hamidi S, Grant CD, Wang CG, Tabish N, Turnipseed SD, et al. Methamphetamine use and emergency department utilization: 20 years later. J Addict. (2017) 2017:4050932. doi: 10.1155/2017/4050932

48. Alam Mehrjerdi Z, Noroozi A. Methamphetamine Intoxication in Emergency Departments of Hospitals in Iran: implications for treatment. Iran J Med Sci. (2013) 38:347-8.

49. Deng X, Huang Z, Li, X, Li Y, Wang Y, Wu D, et al. Long-term follow-up of patients treated for psychotic symptoms that persist after stopping illicit drug use. Shang Archiv Psychiatry (2012) 24:271-8. doi: 10.3969/j.issn.1002-0829.2012.05.004

50. Iwanami A, Sugiyama A, Kuroki N, Toda S, Kato N, Nakatani Y, et al. Patients with methamphetamine psychosis admitted to a psychiatric hospital in Japan. A preliminary report. Acta Psychiatr Scand. (1994) 89:428-32.

51. Nakatani Y, Yoshizawa F, Yamada H, Iwanami A, Sakaguchi M, Katoh N. Methamphetamine psychosis in Japan: a survey. Br J Addict. (1989) 84:1548-9.

52. Teraoka A. [Prognostic and criminological studies on the mental disorder caused by the chronic methamphetamine intoxication]. Seishin Shinkeigaku Zasshi (1967) 69:597-619.

53. Glasner-Edwards S, Mooney LJ, Marinelli-Casey P, Hillhouse M, Ang A, Rawson RA. Psychopathology in methamphetamine-dependent adults 3 years after treatment. Drug Alcohol Rev (2010) 29:12-20. doi: 10.1111/j.1465-3362.2009.00081.x

54. Grelotti D, Kanayama G, Pope H. Remission of persistent methamphetamine-induced psychosis after electroconvulsive therapy: presentation of a case and review of the literature. Am J Psychiatry (2010) 167:17-23. doi: 10.1176/appi.ajp.2009.08111695

55. Arunogiri S, Foulds JA, McKetin R, Lubman DI. A systematic review of risk factors for methamphetamine-associated psychosis. Aust N Z J Psychiatry (2018) 52:514-29. doi: 10.1177/0004867417748750
56. Cadet JL, Gold MS. Methamphetamine-induced psychosis: who says all drug use is reversible? Curr. Psychiatry (2018) 16:15-20.

57. Glasner-Edwards S, Mooney LJ. Methamphetamine psychosis: epidemiology and management. CNS Drugs (2014) 28:1115-26. doi: 10.1007/s40263-014-0209-8

58. Grant KM, LeVan TD, Wells SM, Li M, Stoltenberg SF, Gendelman HE, et al. Methamphetamine-associated psychosis. J Neuroimmune Pharmacol. (2012) 7:113-139. doi: 10.1007/s11481-011-9288-1

59. McKetin R. Methamphetamine psychosis: insights from the past. Addiction (2018) 113:1522-7. doi: 10.1111/add.14170

60. Suetani S, Reddan J, Anderson C. Methamphetamine and psychiatry: a story of the colourless substance of abuse. Aus Psychiatry (2017) 25:254-6. doi: $10.1177 / 1039856217695702$

61. Keefe R. Should cognitive impairment be included in the diagnostic criteria for schizophrenia? World Psychiatry (2008) 7:22-8. doi: 10.1002/j.2051-5545.2008.tb00142.x

62. Blanchard JJ, Cohen AS. The structure of negative symptoms within schizophrenia: implications for assessment. Schizophrenia Bull. (2006) 32:238-45. doi: 10.1093/schbul/sbj013

63. Liemburg E, Castelein S, Stewart R, van der Gaag M, Aleman A, Knegtering $\mathrm{H}$, et al. Two subdomains of negative symptoms in psychotic disorders: established and confirmed in two large cohorts. J Psychiatric Res. (2013) 47:718-25. doi: 10.1016/j.jpsychires.2013.01.024

64. Breier A, Schreiber JL, Dyer J, Pickar D. National Institute of Mental Health longitudinal study of chronic schizophrenia. Prognosis and predictors of outcome. Arch Gen Psychiatry (1991) 48:239-46.

65. Association AP. Diagnostic and Statistical Manual of Mental Disorders, (DSM-5®). Arlington: American Psychiatric Publication (2013).

66. Aleman A, Hijman R, de Haan EH, Kahn RS. Memory impairment in schizophrenia: a meta-analysis. Am J Psychiatry (1999) 156:1358-66.

67. Elvevag B, Goldberg TE. Cognitive impairment in schizophrenia is the core of the disorder. Crit Rev Neurobiol. (2000) 14:1-21. doi: 10.1615/CritRevNeurobiol.v14.i1.10

68. Goldberg TE, Gold JM. Neurocognitive functioning in patients with schizophrenia: an overview. In: Bloom FE, Kupfer DJ. Editors. Psychopharmacology: The Fourth Generation of Progress. New York, NY: Raven Press (1995). pp. 245-1257.

69. Green MF, Kern RS, Heaton RK. Longitudinal studies of cognition and functional outcome in schizophrenia: implications for MATRICS Schizophrenia Res. (2004) 72:41-51. doi: 10.1016/j.schres.2004. 09.009

70. Heinrichs RW, Zakzanis KK. Neurocognitive deficit in schizophrenia: a quantitative review of the evidence. Neuropsychology (1998) 12:426-45.

71. Weickert TW, Goldberg TE, Gold JM, Bigelow LB, Egan MF, Weinberger DR. Cognitive impairments in patients with schizophrenia displaying preserved and compromised intellect. Archiv Gen Psychiatry (2000) 57:90713. doi: 10.1001/archpsyc.57.9.907

72. Bozikas VP, Andreou C. Longitudinal studies of cognition in first episode psychosis: a systematic review of the literature. Aust N Z J Psychiatry (2011) 45:93-108. doi: 10.3109/00048674.2010.541418

73. Dawes SE, Jeste DV, Palmer BW. Cognitive profiles in persons with chronic schizophrenia. J Clin Exper Neuropsychol. (2011) 33:929-36. doi: 10.1080/13803395.2011.578569

74. Lewandowski KE, Cohen BM, Öngur D. Evolution of neuropsychological dysfunction during the course of schizophrenia and bipolar disorder. Psychol Med. (2011) 41:225-41. doi: 10.1017/S0033291710001042

75. Szöke A, Trandafir A, Dupont M-E, Méary A, Schürhoff F, Leboyer M. Longitudinal studies of cognition in schizophrenia: meta-analysis. $\mathrm{Br} \mathrm{J}$ Psychiatry (2008) 192:248-57. doi: 10.1192/bjp.bp.106.029009

76. Barder HE, Sundet K, Rund BR, Evensen J, Haahr U, Ten Velden Hegelstad $\mathrm{W}$, et al. Ten year neurocognitive trajectories in first-episode psychosis. Front Hum Neurosci. (2013) 7:643. doi: 10.3389/fnhum.2013.00643

77. Mesholam-Gately RI, Giuliano AJ, Goff KP, Faraone SV, Seidman LJ. Neurocognition in first-episode schizophrenia: a meta-analytic review. Neuropsychology (2009) 23:315-36. doi: 10.1037/a0014708

78. Saykin AJ, Shtasel DL, Gur RE, Kester DB, Mozley LH, Stafiniak P, et al. Neuropsychological deficits in neuroleptic naive patients with first-episode schizophrenia. Arch Gen Psychiatry (1994) 51:124-31. 
79. Øie M, Sundet K, Rund BR. Neurocognitive decline in early-onset Schizophrenia compared with ADHD and normal controls: evidence from a 13-year follow-up study. Schizophr Bull. (2010) 36:557-65. doi: $10.1093 /$ schbul/sbn 127

80. Goff DC, Hill M, Barch D. The treatment of cognitive impairment in schizophrenia. Pharmacol Biochem Behav. (2011) 99:245-53. doi: 10.1016/j.pbb.2010.11.009

81. Hutton S, Puri B, Duncan L-J, Robbins T, Barnes T, Joyce E. Executive function in first-episode schizophrenia. Psychol Med. (1998) 28:463-73.

82. Minzenberg MJ, Laird AR, Thelen S, Carter CS, Glahn DC. Meta-analysis of 41 functional neuroimaging studies of executive function in schizophrenia. Arch Gen Psychiatry (2009) 66:811-22. doi: 10.1001/archgenpsychiatry.2009.91

83. Mosiołek A, Gierus J, Koweszko T, Szulc A. Cognitive impairment in schizophrenia across age groups: a case-control study. BMC Psychiatry (2016) 16:37. doi: 10.1186/s12888-016-0749-1

84. Rodriguez-Jimenez R, Bagney A, Martinez-Gras I, Ponce G, SanchezMorla EM, Aragues, M, et al. Executive function in schizophrenia: influence of substance use disorder history. Schizophr Res. (2010) 118:34-40. doi: 10.1016/j.schres.2009.09.025

85. Milev P, Ho B-C, Arndt S, Andreasen NC. Predictive values of neurocognition and negative symptoms on functional outcome in schizophrenia: a longitudinal first-episode study with 7-year follow-up. Am J Psychiatry (2005) 162:495-506. doi: 10.1176/appi.ajp.162.3.495

86. Sharma T, Antonova L. Cognitive function in schizophrenia. Deficits, functional consequences, and future treatment. Psychiatr Clin North Am. (2003) 26:25-40. doi: 10.1016/S0193-953X(02)00084-9

87. Dodge HH, Du Y, Saxton JA, Ganguli M. Cognitive domains and trajectories of functional independence in nondemented elderly persons. J Gerontol A Biol Sci Med Sci. (2006) 61:1330-7. doi: 10.1093/gerona/61.12.1330

88. MacNeill SE, Lichtenberg PA. Home alone: the role of cognition in return to independent living. Archiv Phys Med Rehabilit. (1997) 78:755-8. doi: 10.1016/S0003-9993(97)90085-X

89. Jaeger J, Berns S, Loftus S, Gonzalez C, Czobor P. Neurocognitive test performance predicts functional recovery from acute exacerbation leading to hospitalization in bipolar disorder. Bipolar Disord. (2007) 9:93-102. doi: 10.1111/j.1399-5618.2007.00427.x

90. Fillit HM, Butler RN, O’Connell AW, Albert MS, Birren JE, Cotman CW, et al. Achieving and maintaining cognitive vitality with aging. Mayo Clin Proc. (2002) 77:681-96. doi: 10.4065/77.7.681

91. Kittirattanapaiboon P, Mahatnirunkul S, Booncharoen H, Thummawomg P, Dumrongchai U, Chutha W. Long-term outcomes in methamphetamine psychosis patients after first hospitalisation. Drug Alcohol Rev. (2010) 29:456-61. doi: 10.1111/j.1465-3362.2010.00196.x

92. Alderson HL, Semple DM, Blayney C, Queirazza F, Chekuri V, Lawrie SM. Risk of transition to schizophrenia following first admission with substance-induced psychotic disorder: a population-based longitudinal cohort study. Psychol Med. (2017) 47:2548-55. doi: 10.1017/s0033291717 001118

93. Niemi-Pynttari JA, Sund R, Putkonen H, Vorma H, Wahlbeck K, Pirkola SP. Substance-induced psychoses converting into schizophrenia: a register-based study of 18,478 Finnish inpatient cases. J Clin Psychiatry (2013) 74:e94-99. doi: $10.4088 /$ JCP. $12 \mathrm{~m} 07822$

94. Callaghan R, Cunningham J, Allebeck P, Arenovich T, Sajeev G, Remington G. Methamphetamine use and schizophrenia: a populationbased cohort study in California. Am J Psychiatry (2012) 169:389-96. doi: 10.1176/appi.ajp.2011.10070937

95. Connell PH. Amphetamine Psychosis. London: Chapman \& Hall. (1958).

96. Bousman CA, Glatt SJ, Everall IP, Tsuang MT. Genetic association studies of methamphetamine use disorders: A systematic review and synthesis. Am J Med Genet B Neuropsychiatr Genet. (2009) 150B:1025-49. doi: 10.1002/ajmg.b.30936

97. Ikeda M, Okahisa $\mathrm{Y}$, Aleksic B, Won M, Kondo N, Naruse N, et al. Evidence for shared genetic risk between methamphetamine-induced psychosis and schizophrenia. Neuropsychopharmacology (2013) 38:1864-70. doi: 10.1038/npp.2013.94

98. Chen C, Lin S, Sham P, Ball D, Loh E, Murray R. Morbid risk for psychiatric disorder among the relatives of methamphetamine users with and without psychosis. Am J Med Genet B Neuropsychiatr Genet. (2005) 136B:87-91. doi: 10.1002/ajmg.b.30187

99. Flaum M, Schultz SK. When does amphetamine-induced psychosis become schizophrenia? Am J Psychiatry (1996) 153:812-5.

100. Yeh H, Lee Y, Sun H, Wan S. Six months follow-up of patients with methamphetamine psychosis. Zhonghua Yi Xue Za Zhi (2001) 64:388-394.

101. Yui K, Goto K, Ikemoto S, Ishiguro T. Stress induced spontaneous recurrence of methamphetamine psychosis: the relation between stressful experiences and sensitivity to stress. Drug Alcohol Depend (2000) 58:67-75. doi: 10.1016/S0376-8716(99)00060-5

102. Nordahl TE, Salo R, Leamon M. Neuropsychological effects of chronic methamphetamine use on neurotransmitters and cognition: a review. J Neuropsychiatry Clin Neurosci. (2003) 15:317-25. doi: 10.1176/jnp. 15.3.317

103. Potvin S, Pelletier J, Grot S, Hebert C, Barr AM, Lecomte T. Cognitive deficits in individuals with methamphetamine use disorder: a metaanalysis. Addict Behav. (2018) 80:154-60. doi: 10.1016/j.addbeh.2018. 01.021

104. Scott JC, Woods SP, Matt GE, Meyer RA, Heaton RK, Atkinson $\mathrm{JH}$, et al. Neurocognitive effects of methamphetamine: a critical review and meta-analysis. Neuropsychol Rev. (2007) 17:275-97. doi: $10.1007 /$ s11065-007-9031-0

105. Chen CK, Lin SK, Chen YC, Huang MC, Chen TT, Ree SC, et al. Persistence of psychotic symptoms as an indicator of cognitive impairment in methamphetamine users. Drug Alcohol Depend (2015) 148:158-64. doi: 10.1016/j.drugalcdep.2014.12.035

106. Ezzatpanah Z, Shariat SV, Tehrani-Doost M. Cognitive functions in methamphetamine induced psychosis compared to schizophrenia and normal subjects. Iran J Psychiatry (2014) 9:152-7.

107. Hides L, Dawe S, McKetin R, Kavanagh DJ, Young RM, Teesson M, et al. Primary and substance-induced psychotic disorders in methamphetamine users. Psychiatry Res. (2015) 226:91-6. doi: 10.1016/j.psychres.2014.11.077

108. Jacobs E, Fujii D, Schiffman J, Bello I. An exploratory analysis of neurocognition in methamphetamine-induced psychotic disorder and paranoid schizophrenia. Cogn Behav Neurol (2008) 21:98-103. doi: 10.1097/WNN.0b013e31816bdf90

109. McKetin R, Baker AL, Dawe S, Voce A, Lubman DI. Differences in the symptom profile of methamphetamine-related psychosis and primary psychotic disorders. Psychiatry Res. (2017) 251:349-54. doi: 10.1016/j.psychres.2017.02.028

110. Medhus S, Mordal J, Holm B, Morland J, Bramness JG. A comparison of symptoms and drug use between patients with methamphetamine associated psychoses and patients diagnosed with schizophrenia in two acute psychiatric wards. Psychiatry Res. (2013) 206:17-21. doi: 10.1016/j.psychres.2012.09.023

111. Okada N, Takahashi K, Nishimura Y, Koike S, Ishii-Takahashi A, Sakakibara E, et al. Characterizing prefrontal cortical activity during inhibition task in methamphetamine-associated psychosis versus schizophrenia: a multichannel near-infrared spectroscopy study. Addic. Biol. (2016) 21:489-503. doi: $10.1111 / \mathrm{adb} .12224$

112. Shelly J, Uhlmann A, Sinclair H, Howells FM, Sibeko G, Wilson D, et al. First-Rank Symptoms in Methamphetamine Psychosis and Schizophrenia. Psychopathology (2016) 49:429-35. doi: 10.1159/000452476

113. Srisurapanont M, Arunpongpaisal S, Wada K, Marsden J, Ali R, Kongsakon R. Comparisons of methamphetamine psychotic and schizophrenic symptoms: a differential item functioning analysis. Progr Neuro Psychopharmacol Biol Psychiatry (2011) 35:959-64. doi: 10.1016/j.pnpbp.2011.01.014

114. Tomiyama G. Chronic schizophrenia-like states in methamphetamine psychosis. Jpn J Psychiatry Neurol (1990) 44:531-9.

115. Wang LJ, Lin SK, Chen YC, Huang MC, Chen TT, Ree SC, et al. Differences in Clinical Features of Methamphetamine Users with Persistent Psychosis and Patients with Schizophrenia. Psychopathology (2016) 49:10815. doi: 10.1159/000445065

116. Yamamuro K, Makinodan, M, Kimoto S, Kishimoto N, Morimoto $\mathrm{T}$, Toritsuka $\mathrm{M}$, et al. Differential patterns of blood oxygenation in the prefrontal cortex between patients with methamphetamine-induced psychosis and schizophrenia. Sci Rep. (2015) 5:12107. doi: 10.1038/srep12107 
117. Hajebi A, Amini H, Kashani L, Sharifi V. Twelve-month course and outcome of methamphetamine-induced psychosis compared with first episode primary psychotic disorders. Early Interv Psychiatry (2018) 12:92834. doi: 10.1111/eip.12404

118. Ellinwood, E. Amphetamine psychosis: I. Description of the individuals and process. J Nerv Ment Dis. (1967) 144:273-83.

119. Bousman CA, McKetin R, Burns R, Woods SP, Morgan EE, Atkinson JH, et al. Typologies of positive psychotic symptoms in methamphetamine dependence. Am J Addict. (2015) 24:94-7. doi: 10.1111/ajad.12160

120. Fasihpour B, Molavi S, Shariat SV. Clinical features of inpatients with methamphetamine-induced psychosis. J Ment Health (2013) 22:341-9. doi: 10.3109/09638237.2012.745184

121. McKetin R, Dawe S, Burns RA, Hides L, Kavanagh DJ, Teesson M, et al. The profile of psychiatric symptoms exacerbated by methamphetamine use. Drug Alcohol Depend. (2016) 161:104-9. doi: 10.1016/j.drugalcdep.2016.01.018

122. Srisurapanont M, Ali R, Marsden J, Sunga A, Wada K, Monteiro M. Psychotic symptoms in methamphetamine psychotic in-patients. Int J Neuropsychopharmacol. (2003) 6:347-52. doi: 10.1017/S1461145703003675

123. Yui K, Ikemoto S, Ishiguro T, Goto K. Studies of amphetamine or methamphetamine psychosis in Japan: relation of methamphetamine psychosis to schizophrenia. Ann N Y Acad Sci. (2000) 914:1-12. doi: 10.1111/j.1749-6632-2000.tb05178.x

124. Angrist B, Sathananthan G, Wilk S, Gershon S. Amphetamine psychosis: behavioral and biochemical aspects. J Psychiatr Res. (1974) 11:13-23.

125. Bell D. Comparison of amphetamine psychosis and schizophrenia. $\mathrm{Br} \mathrm{J}$ Psychiatry (1965) 111:701-7.

126. Dore G, Sweeting M. Drug-induced psychosis associated with crystalline methamphetamine. Aus Psychiatry (2006) 14:86-9. doi: 10.1111/j.1440-1665.2006.02252.x

127. Yui K, Ikemoto S, Goto K. Factors for susceptibility to episode recurrence in spontaneous recurrence of methamphetamine psychosis. Ann N Y Acad Sci. (2002) 965:292-304. doi: 10.1111/j.1749-6632.2002.tb04171.x

128. Akiyama K. Longitudinal clinical course following pharmacological treatment of methamphetamine psychosis which persists after long-term abstinence. Ann N Y Acad Sci. (2006) 1074:125-34. doi: 10.1196/annals.1369.012

129. Mueser KT, Bellack AS, Brady EU. Hallucinations in schizophrenia. Acta Psychiatr Scand. (1990) 82:26-9.

130. Waters F, Collerton D, ffytche DH, Jardri R, Pins D, Dudley R, et al. Visual Hallucinations in the Psychosis Spectrum and Comparative Information From Neurodegenerative Disorders and Eye Disease. Schizophrenia Bull. (2014) 40:S233-45. doi: 10.1093/schbul/sbu036

131. Rusyniak DE. Neurologic manifestations of chronic methamphetamine abuse. Psychiatric Clinics (2013) 36:261-75. doi: 10.1016/j.psc.2013. 02.005
132. Ali R, Marsden J, Srisurapanont M, Sunga A, Baigent M, Monteiro M. Methamphetamine Psychosis in Australia, Philippines, and Thailand: recommendations for acute care and clinical inpatient management. Addict Disord Their Treatm. (2010) 9:143-9. doi: 10.1097/ADT.0b013e3181cf58f2

133. Foussias G, Agid O, Fervaha G, Remington G. Negative symptoms of schizophrenia: Clinical features, relevance to real world functioning and specificity versus other CNS disorders. Euro Neuropsychopharmacol. (2014) 24:693-709. doi: 10.1016/j.euroneuro.2013.10.017

134. Möller H-J. Clinical evaluation of negative symptoms in schizophrenia. Euro Psychiatry (2007) 22:380-6. doi: 10.1016/j.eurpsy.2007.03.010

135. Bobes J, Arango C, Garcia-Garcia M, Rejas J. Healthy lifestyle habits and 10year cardiovascular risk in schizophrenia spectrum disorders: An analysis of the impact of smoking tobacco in the CLAMORS schizophrenia cohort. Schizophrenia Res. (2010) 119:101-9. doi: 10.1016/j.schres.2010.02.1030

136. Makinen J, Miettunen J, Isohanni M, Koponen H. Negative symptoms in schizophrenia-A review. Nordic J Psychiatry (2008) 62:334-41. doi: 10.1080/08039480801959307

137. Bushnell MC, Goldberg ME, Robinson DL. Behavioral enhancement of visual responses in monkey cerebral cortex. I Modulation in posterior parietal cortex related to selective visual attention. J Neurophysiol. (1981) 46:755-72. doi: 10.1152/jn.1981.46.4.755

138. Akiyama K, Saito A, Shimoda K. Chronic methamphetamine psychosis after long-term abstinence in Japanese incarcerated patients. Am J Addict. (2011) 20:240-9. doi: 10.1111/j.1521-0391.2011.00124.x

139. Mullen JM, Crawford AT. Amphetamine Related Psychiatric Disorders. Treasure Island, FL: StatPearls; StatPearls Publishing StatPearls Publishing LLC. (2018).

140. Farnia V, Shakeri J, Tatari F, Juibari TA, Yazdchi K, Bajoghli H, et al. Randomized controlled trial of aripiprazole versus risperidone for the treatment of amphetamine-induced psychosis. Am J Drug Alcohol Abuse (2014) 40:s10-15. doi: 10.3109/00952990.2013.861843

Conflict of Interest Statement: The authors declare that the research was conducted in the absence of any commercial or financial relationships that could be construed as a potential conflict of interest.

The handling Editor declared a shared affiliation, though no other collaboration, with one of the authors TW at the time of the review.

Copyright (c) 2018 Wearne and Cornish. This is an open-access article distributed under the terms of the Creative Commons Attribution License (CC BY). The use, distribution or reproduction in other forums is permitted, provided the original author(s) and the copyright owner(s) are credited and that the original publication in this journal is cited, in accordance with accepted academic practice. No use, distribution or reproduction is permitted which does not comply with these terms. 